\title{
Laparoscopic approach to acute abdomen from the Consensus Development Conference of the Società Italiana di Chirurgia Endoscopica e nuove tecnologie (SICE), Associazione Chirurghi Ospedalieri Italiani (ACOI), Società Italiana di Chirurgia (SIC), Società Italiana di Chirurgia d'Urgenza e del Trauma (SICUT), Società Italiana di Chirurgia nell'Ospedalità Privata (SICOP), and the European Association for Endoscopic Surgery (EAES)
}

\author{
Ferdinando Agresta - Luca Ansaloni - Gian Luca Baiocchi - Carlo Bergamini - \\ Fabio Cesare Campanile - Michele Carlucci - Giafranco Cocorullo - Alessio Corradi • \\ Boris Franzato • Massimo Lupo • Vincenzo Mandalà - Antonino Mirabella · Graziano Pernazza • \\ Micaela Piccoli · Carlo Staudacher · Nereo Vettoretto $\cdot$ Mauro Zago $\cdot$ Emanuele Lettieri · \\ Anna Levati - Domenico Pietrini - Mariano Scaglione - Salvatore De Masi · Giuseppe De Placido • \\ Marsilio Francucci · Monica Rasi · Abe Fingerhut $\cdot$ Selman Uranüs $\cdot$ Silvio Garattini
}

Received: 1 November 2011 / Accepted: 16 April 2012/Published online: 27 June 2012

(C) Springer Science+Business Media, LLC 2012

\begin{abstract}
Background In January 2010, the SICE (Italian Society of Endoscopic Surgery), under the auspices of the EAES, decided to revisit the clinical recommendations for the role of laparoscopy in abdominal emergencies in adults, with
\end{abstract}

Presented at the 19th International Congress of the European Association for Endoscopic Surgery (EAES), Torino, Italy, June 2011.

\section{F. Agresta $(\square)$}

Department of General Surgery, Presidio Ospedaliero di Adria, Piazza degli Etruschi, 9, 45011 Adria, RO, Italy

e-mail: fagresta@libero.it

L. Ansaloni

Department of General Surgery, Ospedali Riuniti, Bergamo,

BG, Italy

e-mail: lansaloni@ospedaliriuniti.bergamo.it

G. L. Baiocchi

Department of Medical and Surgical Sciences, Surgical Clinic,

Brescia University, Brescia, Italy

C. Bergamini

Department of General, Emergency and Mini-invasive Surgery,

University Hospital of Careggi, Florence, Italy

F. C. Campanile

Department of General Surgery, Ospedale di Civita Castellana,

Civita Castellana, VT, Italy the primary intent being to update the 2006 EAES indications and supplement the existing guidelines on specific diseases.

Methods Other Italian surgical societies were invited into the Consensus to form a panel of 12 expert surgeons. In order to get a multidisciplinary panel, other stakeholders involved in abdominal emergencies were invited along with a patient's association. In November 2010, the panel

\section{Carlucci}

Department of Emergency Surgery, IRCCS San Raffaele, Milan, Italy

\section{G. Cocorullo}

Department of General, Emergency and Transplantation Surgery, A.O.U.P. Paolo Giaccone, Palermo, Italy

\section{A. Corradi}

Department of General Surgery, Regional Hospital of Bolzano,

Bolzano, Italy

B. Franzato

Department of General Surgery, San Giacomo Apostolo Hospital, Castelfranco Veneto, TV, Italy

M. Lupo · V. Mandalà · A. Mirabella

Department of General and Emergency Surgery, "Villa SofiaCervello" Hospital Trust, Palermo, Italy 
met in Rome to discuss each chapter according to the Delphi method, producing key statements with a grade of recommendations followed by commentary to explain the rationale and the level of evidence behind the statements. Thereafter, the statements were presented to the Annual Congress of the EAES in June 2011.

Results A thorough literature review was necessary to assess whether the recommendations issued in 2006 are still current. In many cases new studies allowed us to better clarify some issues (such as for diverticulitis, small bowel obstruction, pancreatitis, hernias, trauma), to confirm the key role of laparoscopy (such as for cholecystitis, gynecological disorders, nonspecific abdominal pain, appendicitis), but occasionally previous strong recommendations have to be challenged after review of recent research (such as for perforated peptic ulcer).

Conclusions Every surgeon has to develop his or her own approach, taking into account the clinical situation, her/his proficiency (and the experience of the team) with the various techniques, and the specific organizational setting in which she/he is working. This guideline has been developed bearing in mind that every surgeon could use the data reported to support her/his judgment.

Keywords Laparoscopy - Acute abdomen · Guidelines

G. Pernazza

Department of General, Laparoscopic and Robotic Surgery, Azienda Ospedaliera San Giovanni Addolorata, Rome, Italy

M. Piccoli

Department of General Surgery, Nuovo Ospedale Civile

S. Agostino Estense Baggiovara, Modena, Italy

C. Staudacher

Department of General Surgery, IRCCS San Raffaele, Milan, Italy

N. Vettoretto

Laparoscopic Surgery Unit, Azienda Ospedaliera "M. Mellini", Chiari, BS, Italy

M. Zago

Minimally Invasive Surgery Unit, Department of General

Surgery, Policlinico Ponte San Pietro, Bergamo, Italy

\section{E. Lettieri}

Department of Management, Economics and Industrial

Engineering, Politecnico di Milano, Milan, Italy

A. Levati

District of Pavia Hospital, Pavia, Italy

D. Pietrini

Institute of Anesthesiology and Intensive Care, Catholic

University Medical School, Rome, Italy
Acute abdominal pain, defined as any medium or severe abdominal pain with duration of less than 7 days, is a common presentation in the surgical department, in both primary-care and secondary referral hospitals. Each year about 450 females and 180 males per 100,000 are hospitalized for acute abdominal pain, the most common causes being nonspecific abdominal pain (NSAP) (15.9-28.1\%), acute biliary disease (2.9-9.7\%), followed by bowel obstruction or diverticulitis [1].

In the last 20 years the role of laparoscopy in emergency surgery has increased. In 2006 the European Association for Endoscopic Surgery (EAES) published [2] its consensus statement on laparoscopy for abdominal emergencies, concluding that “...available evidence clearly demonstrates the superiority of a laparoscopic approach in various emergency situations, but laparoscopy offers less and or unclear benefit in other acute conditions.... Because the EAES updates its guidelines regularly, such data are also important before stronger recommendations can be issued. On the other hand, in those fields for which there is good evidence, laparoscopic surgery has been shown to be highly beneficial...." Almost five years passed since the EAES guidelines publication, and in January 2010, the Scientific and Educational Committee of the SICE (Società Italiana di Chirurgia Endoscopica e nuove tecnologie, Italian Society of Endoscopic Surgery), affiliated with the

M. Scaglione

Department of Diagnostic Imaging, Pineta Grande Medical

Center, Castel Volturno, CE, Italy

S. De Masi

Azienda Ospedaliera-Universitaria Meyer, Florence, Italy

G. De Placido

Department of Gynaecology and Obstetrics, "Federico II"

University, Naples, Italy

M. Francucci

Department of General Surgery, Azienda Ospedaliera

"S. Maria", Terni, Italy

M. Rasi

Registered Nurse, Surgical Operative Theatre Coordinator, Bologna, Italy

A. Fingerhut

Surgical Unit Hippocration Hospital, Athens, Greece

S. Uranüs

Universitätsklinik für Chirurgie, Sektion für Chirurgische

Forschung Auenbruggerplatz 29, 8036 Graz, Austria

S. Garattini

Institute for Pharmacological Research, "Mario Negri”, Milan, Italy 
EAES, decided to revisit the clinical recommendations for the role of laparoscopy in abdominal emergencies in adults, with the primary intent being to update the EAES indications and supplement the existing guidelines on specific diseases and to attain the following objectives: (1) establish the preferred diagnostic procedures, selection of patients, if applicable, and the suitability of the laparoscopic approach responsible for acute abdominal disease settings; (2) assess the indication, morbidity, duration of hospital stay, costs, and recovery time from laparoscopic treatment for acute abdominal settings; and (3) define the optimal practice in laparoscopy for each abdominal emergency and provide recommendations that reflect good practice.

For the purpose of the Consensus, we define an emergent case as unplanned with the need to proceed to surgery immediately (within several hours), once the decision has been made that surgical intervention is necessary or of potential benefit. An urgent case, on the other hand, is one that can be dealt with in a timely manner, and there are cases in which delay until the next day or later is acceptable and does not put the patient at undue risk.

\section{Methods}

\section{Consensus development}

In order to better analyze the existing "evidence" on the subject, other Italian surgical societies ${ }^{1}$ were invited to join the SICE in the Consensus, forming a panel of 12 expert surgeons in emergency surgery, both laparoscopic and open. The involved scientific societies represented the entire Italian surgical community.

The Consensus has been held under the auspices of the EAES. Today it is generally agreed that a multidisciplinary panel is critical to achieve both guidelines and recommendations. Therefore, besides surgeons and the Promoting Committee, radiologists (SIRM, Italian Society of Radiology), anesthesiologists (SIAARTI, Italian Society of Anesthesia, Analgesia, Resuscitation and Intensive Care), gynecologists (SIGO, Italian Society of Gynaecology and Obstetrics), epidemiologists, nurses (IPASVI, the Italian National Federation Nursing Council), health-services researchers, hospital administrators (Federsanità, Italian Federation of Local Health Districts and Municipalities), health managers (SIMM, Italian Hospital Managers

\footnotetext{
${ }^{1}$ Associazione Chirurghi Ospedalieri Italiani (ACOI) (The Italian Society of Hospital Surgeons), Società Italiana di Chirurgia (SIC) (The Italian Society of Surgery), Società Italiana di Chirurgia d'Urgenza e del Trauma (SICUT) (The Italian Society of Trauma and Emergency Surgery), and Società Italiana di Chirurgia nell'Ospedialità Privata (SICOP) (The Italian Private Hospitals' Surgery Society)
}

Society), and health-care regulators (ISS, The Italian National Health Institute) were also involved. A patient's association was also invited and participated (Cittadinanzattiva, Active Citizenship). No pediatric surgeon was involved in the panel because only adult emergency surgery was taken into consideration.

For each disease previously analyzed by the EAES, three experts summarized independently the current state of the art, and their conclusions were made available to the entire panel. Ventral hernia surgery was added as a specific new topic and a paragraph on anesthesiology considerations was also included.

In November 2010 the panel met in Rome for 2 days to discuss each chapter according to the Delphi method, producing key statements each with a grade of recommendation (GoR) followed by a commentary to explain the rationale and the level of evidence behind the statement. All key statements were formulated according to a $100 \%$ consensus obtained within the whole group. Next, these statements were presented to the Annual Congress of the EAES in June 2011 and then the draft document was posted on the websites of all the involved Italian surgical societies for 2 months. Comments from both the audience (about 15) and from the web (almost 100) were collected and partly included in this article as appropriate. The final version of the guidelines was approved by all the members of the panel.

\section{Literature searches and appraisal}

The Oxford hierarchy (March 2009) for grading clinical studies according to levels of evidence (LE) was used to facilitate comparison with the previous EAES consensus (Table 1) (http://www.cebm.net/index.aspx?o=1025). The

Table 1 EAES 2006 and 2011 Guidelines' "evidence" of effectiveness of laparoscopy in acute abdomen

\begin{tabular}{lll}
\hline & 2006 Consensus & 2011 Consensus \\
\hline Perforated gastroduodenal ulcer & +++ & ++ \\
Acute cholecystitis & +++ & +++ \\
Acute pancreatitis & + & ++ \\
Acute appendicitis & +++ & +++ \\
Acute diverticulitis & $-?$ & + \\
Small bowel obstruction & $+?$ & + \\
Incarcerated hernia & $+?$ & + \\
Ventral hernias & & + \\
Mesenteric ischemia & $-?$ & - \\
Gynecologic disorders & +++ & +++ \\
Nonspecific abdominal pain & +++ & +++ \\
Abdominal trauma & $+? /-?$ & + \\
\hline
\end{tabular}

+ , effectiveness from strongest $(+++)$ to weakest $(+) ;-$, no effectiveness; ?, doubtful effectiveness 
primary objective of the search was to identify all clinically relevant randomized controlled trials (RCT). However, other reports, population-based outcomes studies, case series, and case reports were also included. Studies containing severe methodological flaws were highlighted and downgraded as necessary. For each intervention, the validity and homogeneity of study results, effect sizes, safety, and economic consequences were considered.

A systemic review based on a comprehensive literature research was made on PubMed. The Limits Activated included Humans, Clinical Trial, Meta-Analysis, Practice Guideline, Randomized Controlled Trial, Review, English, All Adult: $19+$ years, published in the last 5 years. The search details were [(("laparoscopy"[MeSH Terms] OR "laparoscopic"[All Fields]) AND ("condition-specific key word" [MeSH Terms] OR "condition-specific key word"[All Fields])) AND ("humans"[MeSH Terms] AND (Clinical Trial[ptyp] OR Meta-Analysis[ptyp] OR Practice Guideline[ptyp] OR Randomized Controlled Trial[ptyp] OR Review[ptyp]) AND English[lang] AND “adult"[MeSH Terms] AND “2005/1/1”[PDat]: “2010/11/25”[PDat])].

Full texts from selected abstracts were used based on specific criteria. The papers were selected and classified by two researchers in duplicate on the basis of highest level of evidence, design of the study, and most recent publication. Subsequently, limits regarding language, age, publication data, and study type were removed and a second screening of the titles was performed in order to include other papers that could be of interest in the specific topic.

Crosslink control was performed with Google Scholar and Cochrane library databases.

According to the Health Technology Assessment Programme Manual (2001) [3], clinical recommendations are defined as "systemically developed statements to assist both the practitioner and patient decisions in specific circumstances... Guidelines are viewed as useful tools for making care more consistent and efficient and for closing the gap between what clinicians do and what scientific evidence support...." We agree with what is reported in the SIGN [4] and SNLG [5] manuals: “...clinical guidelines do not rob clinicians of their freedom, nor relieve them of their responsibility to make appropriate decisions based on their own experience and according to the particular circumstances of each patient. It is stressed that the standard of care required by Law derives from customary and accepted practice rather than from the imposition of practices through clinical guidelines.... Guidelines are intended as an aid[sic] to clinical judgment not to replace it...."

The Consensus development guidelines were reviewed in draft form by independent expert referees Prof. Uraneus and Prof. Fingerhut for the EAES and the methodology was reviewed by Prof. Silvio Garattini for the Istituto Mario Negri-Italian Cochrane Center.

\section{Results}

Acute cholecystitis

Patients with acute cholecystitis should be treated by laparoscopic cholecystectomy (GoR A). Severe (gangrenous, empyemic) cholecystitis and advanced age do not preclude the indication for laparoscopic cholecystectomy (GoR B). Surgery should be performed as soon as possible after the onset of symptoms (GoR A). Early laparoscopic surgery should be offered also to elderly patients (GoR B). In patients with severe comorbidities, conservative treatment or percutaneous cholecystostomy, followed or not by early or delayed surgery, may be alternatives in order to reduce surgical or anesthetic risks (GoR C).

Diagnosis of acute cholecystitis relies on a combination of local clinical signs, systemic signs of inflammation, and imaging findings. Very similar sets of criteria with almost $100 \%$ specificity have been suggested in the EAES guidelines of 2006 [2] and in the Tokyo Consensus Meeting Guidelines [6]: both can be used in clinical practice.

The safety of laparoscopic cholecystectomy for acute cholecystitis has been shown in several studies. The EAES consensus statement published in 2006 [2] discussed the evidence from two randomized trials (LE 1b) [7, 8] and several comparative studies demonstrating faster recovery and shorter hospital stay in favor of laparoscopy. A recent US population-based research outcome study, conducted over a 6-year period (LE 2c) [9], indicated that laparoscopic cholecystectomy was associated with lower morbidity, lower mortality, and shorter hospital stays than open cholecystectomy.

However, it may be argued that the better outcomes of laparoscopic cholecystectomy patients may be due to the medical staff's attitude toward expectation of faster recovery rather than to true physiopathological changes (expectation bias). The only trial that included a blind assessment of outcomes (by concealment of wounds both to patients and postoperative care staff) [8] showed very similar postoperative outcomes in both groups, but still demonstrated a shorter postoperative hospital stay for the laparoscopic group. Moreover, recent randomized studies evaluated the influence of surgical trauma on systemic inflammation, and immune response in acute cholecystitis demonstrated that a laparoscopic approach caused less surgical trauma and immunosuppression (LE 1b) [10, 11].

The question arises as to whether laparoscopic surgery is indicated for severe cholecystitis (gangrenous, empyemic, or perforated). In a recent review of prospective and retrospective series (LE 2a) [12], local postoperative complications were not increased: laparoscopic cholecystectomy can be considered an acceptable indication for severe 
cholecystitis despite a threefold higher conversion rate. Subtotal cholecystectomy appears to be an acceptable alternative in patients with intense inflammation and increased risk of damage to the structures in Calot's triangle (LE 2a) [13].

Another subgroup that deserves a separate analysis is the elderly population. The number of elderly patients with acute cholecystitis has been increasing over the years, and earlier reports suggested increased morbidity and a higher conversion rate for laparoscopic cholecystectomy in the elderly [14] and also increased mortality. However, it is very difficult to extrapolate data from series involving both acute and chronic gallbladder disease [15, 16] or from those comparing younger and older patients [17, 18] because acute biliary disease appears to be more severe in older patients and the overall prevalence of comorbidities is higher. Several prospective and retrospective comparative studies comparing laparoscopic versus open surgery for acute cholecystitis in elderly patients suggested a reduction in the length of hospitalization [19-21], with either unchanged [19] or improved morbidity (LE 2b) [20-22].

The optimal timing of surgical intervention in acute cholecystitis is a major issue. Randomized controlled trials comparing early versus delayed open cholecystectomy have found that early surgery was associated with a lower complication rate and a shorter hospital stay [23-26]. However, earlier reports suggested an increased risk of conversion and intraoperative complications such as bile duct injury if acute cholecystitis was treated early by laparoscopic cholecystectomy [27, 28]. Since the late 1990s, at least seven papers [29-35] analyzed in five meta-analyses (LE 1a) [36-41] have been published. Six of those seven papers were RCTs (LE 1b), but one of the systematic reviews [38] included a nonrandomized study (LE 2b) [34]. Another RCT (LE 1b) was not included in any systematic review because it was published at a later date [42]. The definition of time interval for early or delayed surgery varies among the studies taken into consideration: "early" ranged from 4 to 7 days after the onset of symptoms, while delayed treatment was defined as 6-12 weeks after index admission. In one of the studies [32], the delayed treatment group included patients operated on after resolution of symptoms or within 5 days if the symptoms failed to resolve; those patients would have been included in the "early" group in the other trials; however, this study was not analyzed in three of the five systematic reviews. Despite these methodological issues, all studies reached the same conclusions: early treatment reduced total hospital stay and did not increase the complication or conversion rates (LE 1a). Of the patients included in the delayed surgery groups, $17.5 \%$ (range $=13.9-25 \%$ ) required urgent surgery during the interval period, because of failure of conservative treatment or for recurrent symptoms after discharge. In this subset of patients, the conversion rate was $45 \%$. These data underscore the trend toward early surgery.

Despite the large number of studies addressing the issue of laparoscopic cholecystectomy in the elderly, only one retrospective trial examined the results of early versus delayed treatment in the aged and it found no statistically significant difference in outcome between the two groups [43]. A recent study examined a sample of the US Medicare Claims Data System and found that $75 \%$ of patients aged 66 years and older, admitted as emergencies to an acute-care facility for a first episode of acute cholecystitis, were treated by early cholecystectomy (71\% laparoscopic and $29 \%$ open) [44]. The widespread use of early laparoscopic cholecystectomy in elderly patients, at least in the US, confirms that most surgeons are confident in performing early laparoscopic surgery for acute cholecystitis, even in an aged population. Furthermore, the same outcome analysis showed that lack of definitive treatment during initial hospitalization in the elderly is associated with a $38 \%$ gallstone-related readmission rate over the subsequent 2 years (with only $9.5 \%$ of patients undergoing an elective outpatient cholecystectomy) compared with $4.4 \%$ in patients who underwent early treatment (LE 2c).

Several alternatives have been proposed for emergency treatment in high-risk septic patients unfit for emergency surgery: conservative treatment (LE 1b) [45], tube cholecystostomy followed by early laparoscopic surgery (LE 1b) [46], (LE 4) [47] or delayed open surgery (LE 4) [48], and cholecystostomy alone (LE 4) [49]. A systematic review of 53 papers on cholecystostomy as an option in acute cholecystitis (LE 2a) found no evidence to support the recommendation of percutaneous drainage rather than early emergency cholecystectomy, even in critically ill patients, and actually suggested that cholecystectomy seems to be a better alternative for treating acute cholecystitis in the elderly and/or critically ill population [50].

Two cost-utility analyses were published. One of them, performed in a prospective randomized trial, found no significant difference in the cost or outcomes of early laparoscopic cholecystectomy versus delayed treatment, with the latter favored by the incremental cost per additional Quality Adjusted Life Year (QALY); however, patients operated on for biliary colic were included in the trial (LE 1b) [51]. A model-based economic evaluation to estimate costs and outcomes used data from a Cochrane review [39] and showed that early surgery was less expensive and results in better quality of life than delayed treatment (LE 1b) [52].

The role of intraoperative cholangiography in reducing common bile duct (CBD) lesions remains controversial. The literature on the topic includes several population- 
based studies; in all of them patients with acute cholecystitis are included in a larger series, obtained from administrative databases, along with elective cholecystectomies. The population extracted from administrative databases is necessarily heterogeneous and comprises groups that adopt a routine use or a selective use of intraoperative cholangiography, besides patients in which the test had been obtained when a CBD lesion was already suspected. For these reasons the relationship between intraoperative cholangiography and lower CBD injury has to be considered, and the evidence on this issue, in particular as far as acute cholecystitis is concerned, is low [53-56].

A RCT of traditional electrocautery dissection versus ultrasonic dissection demonstrated that operative time in laparoscopic cholecystectomy performed for acute cholecystitis was significantly shorter when ultrasonic dissection was used (LE 1b) [57]. A prospective observational study confirmed this finding and showed a reduction in conversion rates for acute cholecystitis patients operated on laparoscopically with ultrasonic dissection (LE 2b) [58]. A randomized trial on this topic is currently underway to clarify these observations [59].

We could not find any trial that compared results of conventional laparoscopic surgery versus single-access surgery for acute cholecystitis. A randomized trial of early minilaparoscopic versus conventional laparoscopic surgery did not find any statistically significant difference between the two techniques with respect to conversion rates, mean duration of the operation, hospital stay, and major complications; however, the study was not based on intention to treat and the converted cases were excluded from the analysis (LE 2b) [60].

\section{Acute pancreatitis}

In mild gallstone-associated acute pancreatitis, laparoscopic cholecystectomy should be performed as soon as the patient has recovered and during the same hospital admission (GoR B). In severe gallstone-associated acute pancreatitis, laparoscopic cholecystectomy should be delayed until there is sufficient resolution of the inflammatory response and clinical recovery (GoR B). Apart from cases in which an emergency ERCP is indicated, in case of CBD stones, clearance should be obtained by preoperative ERCP or by laparoscopic removal of bile duct stones during cholecystectomy (GoR A). When pancreatic necrosis requires treatment for clinical signs of sepsis or multiorgan failure that does not improve despite optimal therapy, a step-up approach consisting of percutaneous drainage, followed, if necessary, by minimally invasive retroperitoneal debridement should be undertaken. Open surgery should be reserved to patients not responding to minimally invasive treatment (GoR B). The abdominal compartment syndrome should be managed by prompt laparostomy or fasciotomy; laparoscopy is formally contraindicated in these cases (GoR C).

A number of guidelines have been published on the management of acute pancreatitis (AP), including those produced by the Italian Association for the Study of the Pancreas [61]. However, only the guidelines of the EAES, published in 2006 [2], specifically address the laparoscopic management of AP.

Acute pancreatitis is a frequent condition [62, 63], presenting with a wide spectrum of clinical features. Assessment of severity is mandatory, and it is usually performed by APACHE II score or CT scan (LE 2b) [64-66].

In gallstone pancreatitis, laparoscopic cholecystectomy is indicated to prevent disease recurrence. In mild pancreatitis, cholecystectomy should be considered as soon as the patient has recovered and during the same hospital admission, while in severe pancreatitis cholecystectomy is delayed until there is sufficient resolution of the inflammatory response and clinical recovery (LE 2b) [67-73].

When CBD stones are suspected, confirmation with endoscopic ultrasonography (EUS) or magnetic resonance cholangiography (MR) should be obtained whenever possible [74, 75]. EUS and MR allow detection of CBD stones with sensitivity and specificity both over $90 \%$, avoiding unnecessary bile duct exploration [76]. If the diagnosis of CBD stones is confirmed, they can be managed by preoperative endoscopic retrograde cholangiopancreatography (ERCP) [77], laparoscopic CBD clearance during cholecystectomy (laparoscopic or combined laparoendoscopic "rendezvous") [78, 79], or at the next best opportunity. Two meta-analyses showed no differences when preoperative ERCP was compared to intraoperative removal of CBD stones (LE 1b) [80, 81]. The choice of treatment should be determined by the surgeon, since laparoscopic CBD exploration requires substantial surgical skills.

Radiological drainage and/or surgery are indicated to treat infected pancreatic necrosis with clinical signs of sepsis and sterile pancreatic necrosis with multiorgan failure if the necrosis does not improve despite maximal therapy [61]. The treatment of necrosis should be delayed by at least 14 days from the onset of pancreatitis $[61,82]$. When surgery is indicated, traditional necrosectomy through laparotomy can be performed, but less invasive approaches have recently been gaining surgical attention. Laparoscopic debridement can be performed through an infracolic [83] or retroperitoneal approach [84, 85]; transgastric endoscopic pancreatic necrosectomy has also been reported [86]. Two recent prospective studies (one singlearm [87] and one randomized [88]) suggested that the presence of a well-demarcated necrosis can be treated 
using a step-up approach whenever possible (LE 1b). The first step should be percutaneous drainage, followed, whenever needed, by minimally invasive retroperitoneal debridement. Open surgery should be the last step, to be performed in cases where more conservative treatment has failed. This strategy has been associated with a significantly lower morbidity (diabetes, incisional hernias) and lower new-onset multiple-organ failure when compared to open surgery as the first step [88].

The only indication for early surgery in acute pancreatitis is the presence of a compartment syndrome [89-91], which should be managed by surgical decompression (laparostomy or fasciotomy) (LE 4); laparoscopy is formally contraindicated in these cases.

\section{Acute appendicitis}

Patients with symptoms and diagnostic findings suggestive of acute appendicitis should undergo diagnostic laparoscopy (GoR A) and, if the diagnosis is confirmed, laparoscopic appendectomy (GoR A).

More than 25 years after the first laparoscopic appendectomy (LA) [92], its technical aspects and outcomes are still debated, despite recent guidelines [93, 94]. Preoperative ultrasound, in addition to clinical examination and CT in equivocal cases (LE 2b), seems to lower the negative appendectomy rate and missed perforations [95, 96]. Antibiotic therapy alone has not proven superior to surgery for the treatment of appendicitis (LE 1a) due to the higher rate of readmission and surgery in the first year [97]. LA can be considered the gold standard in premenopausal women (LE 1a) [98], and it is feasible in the elderly (LE 3) [99] and the obese (LE 3) [100], but in men LA has no advantages compared with open appendectomy (OA) (LE 1b) [101]. Complicated appendicitis can be approached laparoscopically, with significant improvement of the surgical site (SS) infection rate (a minor advantage according to Clavien's criteria) (LE 3a) [102, 103]. Thorough peritoneal lavage ( $>6-8 \mathrm{~L}$ ) and aspiration are recommended in complicated appendicitis (LE 5) in order to minimize the abscess formation rate [104]. The reported increase in postoperative intra-abdominal abscesses [98] is probably due to initial experiences and has not been confirmed by more recent reviews (LE 2a) [105]. Despite evidence that considers LA safe in pregnancy [106], advantages are minor (less pain, fewer infections, fewer early deliveries) when compared to the risk of fetal loss, which seems greater with LA than with OA (LE 2) [107]. Removal of a normal appendix in the presence of other diseases at exploration is not recommended. If no other disease is encountered and the appendix appears "normal," (1) remove the appendix if there is a preoperative history of appendicular colicky pains and a preoperative exam (US or
CT) reveals suspected fecalith or fecal impaction in the appendix (LE 4) [108], and (2) morbidity of appendectomy does not significantly exceed that of the explorative laparoscopy. If the practice's rate of abscesses is minimal, then appendectomy is advised in order to prevent recurrent pain and readmission (up to 13 and $9 \%$, respectively) and to gain the "endoappendicites," which account for 11-26\% of normal appendices at pathologic examination (LE 5) [109].

Regarding appendiceal stump closure, stapling has been found to reduce operative time and superficial wound infections (LE 1a) [110], but since there is no evidence to prove a lower rate of deep abscess with the use of staplers, higher costs may influence the choice toward loop closure. Cochrane protocol results (stapler vs. loop, primary outcome deep abscess rate) are awaited [111]. Nevertheless, attention must be paid to training results with the two methods apart from comparative costs. In fact, LA is performed mostly by young and less experienced surgeons during late afternoon or nighttime; therefore, an easier and technically standardized method such as the mechanical stapler might prove to be advantageous (LE 5) [94].

Three-port appendectomy is still the laparoscopic gold standard. Various trocar sites and sizes can be used: in young women umbilical and two suprapubic trocars have been suggested to provide better cosmetic results (LE 5) [94]. Needlescopy should be applied only in selected and noncomplicated cases due to the higher rate of conversion and prolonged operating room time associated with it (LE 1a) [112]. Trocar incisions should follow Langer's lines to achieve better cosmetic results (LE 5) [113]. Single-port appendectomy is still inferior to the standard three-port technique (LE 3b) [114]. NOTES appendectomy (via natural orifices) is performed only in strictly controlled clinical and experimental protocols [115]. Fast-track procedures in the postoperative care of LA patients should be studied and implemented (LE 5) [116]. Costs should not be the determining factor in favoring open or LA, unless there is a routine application of costly technology due to the surgeons' choice (LE 2a) $[117,118]$. The panel believes that standardization of the technique is of utmost importance to improve the quality of future trials regarding LA and also for teaching and training purposes (LE 5) [93, 119].

Gynecologic disorders

When gynecologic disorders are the suspected cause of abdominal pain, diagnostic laparoscopy (DL) should follow conventional diagnostic investigations, especially US (GoR A), and, if needed, a laparoscopic treatment of the disease should be performed (GoR A).

Close cooperation with the gynecologist is strongly recommended (GoR A). 
Close cooperation with the gynecologist in the setting wherever available in the field of gynecological emergencies was recommended in the previous EAES Guidelines without any further supportive evidence.

The most common diagnoses encountered in female patients with acute lower abdominal and/or pelvic pain are [120] ectopic pregnancy (EP), adnexal torsion (AT), endometriosis, pelvic inflammatory disease (PID), and hemorrhagic ovarian cysts. Many acute gynecological diseases can be approached safely and effectively with laparoscopy, with the aim not only to correctly diagnose the diseases but also to treat them (LE 4) [121-132].

In gynecological emergencies, transvaginal and conventional ultrasound (US) with the aid of a pregnancy test can formulate a differential diagnosis in a high percentage of patients (LE 3b) [133]. CT and MR scans are very rarely useful (LE 2b) [134-137]. However, DL is better than US (LE 2b) $[123,128,130,133,138]$ and may lead to the modification of an incorrect preoperative diagnosis in up to $40 \%$ of cases (LE 4) [124, 128, 130, 139, 140]. Early DL results in the accurate, prompt, and efficient management of acute abdominal pain, particularly in general practice, where it reduces the rate of unnecessary laparotomy and right iliac fossa gridiron incisions and increases diagnostic accuracy (LE 4) [122, 123, 125-127]. In particular, DL has been shown to reduce the risk of a negative appendectomy when appendicitis is suspected, with a stronger effect in fertile women, mainly due to the correct diagnosis of gynecological disorders (LE 1a) [98, 141].

Ectopic pregnancy (EP) is a potentially life-threatening condition. Approximately 1/100 pregnancies are ectopic, with the embryo usually implanted in the fallopian tube. Some EPs resolve spontaneously, but others continue to grow and lead to rupture of the tube. Risks are higher in women with damage to the fallopian tubes due to pelvic infections, surgery, or previous EP [142]. In women in early pregnancy presenting with acute pelvic pain and/or vaginal bleeding, a diagnosis of EP should always be considered. Current diagnosis of tubal EP involves a combination of transvaginal US and measurement of serum human chorionic gonadotropin (hCG) concentrations. In the vast majority of cases, a pregnancy test can exclude the diagnosis in cases with only minor symptoms. However, accurate and early ascertainment remains problematic, and there are often delays in making the diagnosis and implementing treatment. Further difficulties are encountered because serial hCG determination cannot accurately distinguish arrested intrauterine pregnancy from tubal EP. Although laparoscopy can be required occasionally to confirm the diagnosis of EP, we emphasize that this procedure is not without risk. On the other hand, in women in early pregnancy presenting with acute pelvic pain and/or vaginal bleeding with inconclusive diagnosis of EP after
hCG concentrations and US, a DL can be considered to exclude EP (LE 5) [133, 143].

There are three options for the management of tubal EP: surgery, medical treatment, and expectant management. These options should be evaluated in terms of treatment success (i.e., complete elimination of trophoblastic tissue), financial costs, and future fertility. Laparoscopic salpingectomy should be performed in cases of ruptured tubal EP. In cases of unruptured tubal EP, a tube-preserving operation (laparoscopic salpingostomy) should be considered. Hemodynamic instability is a contraindication for laparoscopy. In EP, an alternative nonsurgical treatment option in selected patients with low serum hCG concentrations is medical treatment with systemic methotrexate (MTX). Expectant management cannot be adequately evaluated yet (LE 1a) [143-146]. In particular, in patients with EP, laparoscopic surgery should be undertaken because its total cost is less (LE 1b) [147]. It is fast and fertility outcome is comparable to laparotomy. Furthermore, sick leave and hospitalization are shorter and adhesion development is minor compared to laparotomy (LE 1b) [148-152].

The diagnosis of $A T$ is missed in half of the cases. After excluding pregnancy, a transvaginal US is mandatory to exclude ovarian cyst formation. In cases with persistent pain and/or if a larger cyst is seen on ultrasound, a DL may be performed to exclude AT (LE 5) [133]. When AT, an organ-threatening disease, is suspected, urgent surgical intervention is indicated. Despite the "necrotic" appearance of the twisted ischemic ovary, detorsion is the only procedure that should be performed at surgery. Adnexectomy should be avoided as ovarian function is preserved in 88-100\% of cases [153]. Laparoscopy for ovarian conservation is recommended to treat patients with AT because of its associated shorter hospital stay, fewer postoperative complications, and ovarian preservation (LE 2b) [154-156]. When ovarian cysts are found during DL, they should be treated laparoscopically (LE 1a) [157-159]. Laparoscopic surgery was also reported to be superior compared to open surgery for resecting other types of ovarian cysts (LE 1b) [160].

Endometriosis can cause dysmenorrhea, dyspareunia, noncyclic pelvic pain, and subfertility. The estimated prevalence of endometriosis in the general population is 1.5-6.2 \%, but in women with dysmenorrhea, the incidence of endometriosis is 40-60\%, and in those with subfertility it is $20-30 \%$ [161]. Symptoms and laparoscopic appearance do not always correlate. Pain is usually chronic and recurrent, but some patients present with acute symptoms [162]. In comparison with the histopathology, laparoscopy alone showed $97.7 \%$ sensitivity, $79.2 \%$ specificity, $72 \%$ positive predictive value, and $98.4 \%$ negative predictive value. (LE 2b) [162]. Surgical treatment may be indicated 
in some patients and may be performed as an open procedure or laparoscopically, although no trials have compared the two approaches (LE 5) [163]. More evidence is available on the comparative effectiveness of laparoscopic excision versus conservative treatment of endometriosis. Although these studies included elective rather than emergency patients, their results indicate that laparoscopic excision results in clear and patient-relevant advantages as opposed to conservative treatment (LE 1a) [164-166].

Pelvic inflammatory disease (PID) describes the clinical features of sexually transmitted pelvic infection ranging from acute salpingitis to salpingo-oophoritis and ultimately tubo-ovarian or pelvic abscess, which may lead to both subfertility and tubal EP. Laparoscopy has demonstrated that PID is the cause of NSAP in $13 \%$ of young women (LE 1b) [167]. Laparoscopy can be considered the definitive diagnostic modality and is useful for excluding other pathologies, which may be present in approximately $20 \%$ of patients (LE 4) [168], but we underscore that this invasive procedure is not suitable for routine clinical practice, especially in the primary-care setting. Microbiological specimens should be taken to guide antibiotic therapy (LE 3b) [169].

In women of reproductive age, tubo-ovarian abscess is one of the most common types of pelvic abscess. Tuboovarian abscesses are classically treated with broad-spectrum antibiotics. In about $25 \%$ of the cases, this approach fails and surgical intervention becomes necessary. Surgical procedures include laparotomy or laparoscopy with drainage of the abscess, unilateral or bilateral salpingo-oophorectomy, and hysterectomy. However, surgery for tuboovarian abscess is often technically difficult and associated with complications (LE 4) [170, 171]. An alternative approach is the use of imaging-guided drainage of the abscess in combination with antibiotics: a RCT indicates that US-guided transvaginal drainage with concomitant antibiotics is especially safe and efficacious (LE 1b) [172]. Depending on the severity of symptoms, laparoscopy is therefore considered to be advantageous in selected cases of acute salpingitis (LE 4) [169, 173] and tubo-ovarian abscess (LE 4) [174].

Initial management of a suspected follicular or hemorrhagic cyst is supportive management and continued observation with a repeat pelvic ultrasound in approximately 4-6 weeks to document resolution. Indications for immediate operative intervention include a large amount of peritoneal fluid found on transvaginal ultrasound, hemodynamic instability, and severe pain. Delayed operative management is indicated for patients in whom pain does not improve with conservative management or for persistent tumors to rule out a neoplastic process. A cystectomy is recommended as opposed to a unilateral salpingooophorectomy in reproductive-aged women. Laparoscopic evaluation is usually feasible; however, if cancer is suspected, laparotomy may be necessary to ensure complete removal and for staging purposes (LE 5) [121]. Laparoscopic surgery advantages over laparotomy include shorter hospital stay without increased adverse events (LE 2b) [175].

Nonspecific abdominal pain

\section{Diagnostic laparoscopy is technically feasible and can be applied safely for selected patients with acute NSAP after a complete diagnostic work-up (GoR A).}

NSAP is defined as acute abdominal pain lasting less than 7 days and for which diagnosis remains uncertain after baseline examination and diagnostic tests [176]. Although attempts have been made toward developing consensus guidelines and diagnostic algorithms, no evidence-based clinical guidelines about NSAP have been developed or validated to date [177, 178].

Recently, enhanced or nonenhanced CT of the abdomen and pelvis has been proposed as a particularly useful adjunct in the initial assessment of patients with NSAP (LE 1b) $[179,180]$. Several studies have documented the feasibility and safety of DL under general anesthesia for patients with acute abdominal pain (LE 1b) [181, 182]. The diagnostic accuracy of the procedure is high, ranging between 90 and $100 \%$ (LE 2a) [183] and prevents unnecessary laparotomies in 36-95\% of patients in the published series (LE 3b) [183]. Overall morbidity, including in ICU patients, has been reported to be between 0 and $8 \%$ in expert hands, and no mortality directly associated with the procedure has been reported (LE 2b) [184, 185]. Contraindications for DL do not differ from contraindications for exploratory laparotomy [183].

The role of early laparoscopy compared with the traditional "wait and see" in the management of NSAP in patients with unclear diagnosis after baseline examinations and tests has been evaluated by randomized controlled trials [167, 186, 187], with controversial results due to small sample size or absence of long-term follow-up. DL seems to improve the diagnosis rate (81-97 vs. $28-36 \%$ in an observational group), and subsequent treatment of patients with NSAP leads to reduced hospital stays (LE $2 \mathrm{~b}$ ), but two controlled trials failed to show that DL is useful in preventing the recurrence of symptoms (LE 1b) [167, 188].

The available literature has a number of limitations, including the lack of homogeneity in the reported patient populations and the frequent absence of high-quality preoperative imaging studies, which could have provided the diagnosis without the need for an invasive procedure. Furthermore, better-quality research is needed to evaluate the definitive role of DL in patients with acute NSAP. 
Perforated peptic ulcer

Laparoscopy is a useful diagnostic tool when preoperative findings are not conclusive, especially if a laparoscopic treatment is likely (GoR A). Laparoscopy is a possible alternative to open surgery in the treatment of perforated peptic ulcer (GoR B).

The diagnosis of a perforated peptic ulcer (PPU) is based on clinical history, clinical examination, and instrumental investigations. A CT scan of the abdomen is the most reliable exam, not only for the diagnosis of perforation (sensibility nearly $100 \%$ for the detection of pneumoperitoneum), but also to identify the perforation site (specificity approximately $86 \%$ ) (LE 2b) [189-191]. A DL is possible when preoperative exams are not sufficiently clear for definitive diagnosis (LE 1a) [122, 192, 193]. However, failing to identify a PPU represents one of the most frequent causes of conversion to laparotomy (LE 1a) [194].

To date, there is no unanimous agreement about which group of patients might benefit from a laparoscopic approach to PPU. Several studies suggest that Boey's shock score on admission [blood pressure (BP) $<90 \mathrm{mmHg}$ ), ASA III-V (severe comorbidities), and duration of symptomatology (>24 h) $[195,196]$ are the most reliable parameters for selecting patients (LE 3b). The laparoscopic approach is safe in patients with no risk factors $($ Boey score $=0)($ LE 1a) [192]. Other principles of selection have been considered: Mannheim Peritonitis Index (MPI) (LE 2b) [197], age $>70$ years (LE 3b) [196], APACHE II (LE 3b) [198], and surgeon's skill in miniinvasive surgery.

The choice of perforation closure technique depends on lesion characteristics: if margins are edematous, friable, and/or difficult to mobilize, repair can be limited to an omental patch, eventually associated with one or more sealant devices (LE 5) [199]; when the margins can be easily brought together, without tension, direct suturing can be sufficient with or without omentoplasty (LE 3a) [200]. To make the PPU repair simpler, and consequently reducing operating times, a "sutureless" technique has been proposed, eventually associated with sealant devices [199]. However, debate exists about whether the reduction of operating times by simplified techniques could be a patient safety issue, with a higher incidence of postoperative complications (especially leakage) (LE 5).

Decontamination of the peritoneal cavity by washing after treatment of PPU is a fundamental step in the surgical procedure (LE 1a) [200].

Predictive factors of conversion are shock on admittance and the free interval between the beginning of perforation and the diagnosis $>24 \mathrm{~h}$ (LE 2b) [201-203].
In Lau's meta-analysis [194], the reoperation rate was higher after the laparoscopic approach $(3.7 \%)$ than after conventional surgery (1.6\%) (LE 1a). Suture site leakage represents the most important cause of reoperation (LE 1a). Lee APACHE II (5 points) and ulcer size $(>10 \mathrm{~mm})$ are independent risk factors for postoperative leak after laparoscopic sutureless fibrin glue repair (LE 3b) [198]. A systematic review by Lunevicius [192] reported a reoperation rate for the laparoscopic approach nearly double that for open surgery (5.3 vs. $2.1 \%$ ). The results of these studies, due to many biases, are not enough to definitively clarify the role of the laparoscopic repair for PPU. Further trials are needed.

One of the advantages of laparoscopic surgery is less postoperative pain (LE 1a) [192, 199, 204], but earlier data [199] about pain (within $24 \mathrm{~h}$ postoperatively) did not show any difference, probably because of peritoneal inflammation. Recent reports [200] confirms a decrease in the incidence of complications (abdominal wall complications, prolonged postoperative ileus, pulmonary infection, and mortality rate) with laparoscopic surgery compared to open surgery. On the other hand, a greater incidence of intra-abdominal fluid collection (due mostly to leakage at the suture site) has been reported. However, none of these differences are statistically significant [200]. The operative times are longer for laparoscopy (LE 1b) [199, 205] (except one study [193]); however, a progressive and constant reduction of operative times over the past 10 years has been seen, probably due to an improvement in the surgeon's skill, better technology, and better organization of the surgical teams. The hospital stay has been shown to be more favorable for the laparoscopic approach compared to traditional surgery in Siu et al. [193] but not in Lau [199] and Bertleff et al. [205].

Acute diverticulitis

Laparoscopic approach with lavage and drainage is indicated in complicated diverticulitis Hinchey I and IIa (when percutaneous drainage failed and when indicated for clinical deterioration) and Hinchey IIb and III (GoR B). In Hinchey IV diverticulitis, as well as Hinchey III when lavage and drainage is not advised, a colonic resection may be indicated, with or without diverting protection stoma, which may be performed laparoscopically, depending on the general conditions of the patient and on the skill of the operator (GoR C).

The diagnosis of acute diverticulitis can be suspected clinically by physical examination and blood count findings and can be confirmed by CT scan. Uncomplicated disease is defined as an inflammatory process limited to the colon, including signs such as wall thickening and inflammation of the pericolic fat. Patients with acute uncomplicated 
diverticulitis should be treated conservatively with antibiotics and not undergo emergency surgery (LE 2a) [206, 207]. Following recovery, a study of the colon should be performed to evaluate the extension of diverticular disease and to rule out alternative diagnoses such as ischemic colitis, inflammatory disease, or colonic cancer. Optical colonoscopy, barium enema, and CT colography (the so-called virtual colonoscopy) may all be employed, but the latter provides data about the bowel and the surrounding tissues and organs as well. When elective sigmoid resection is indicated, laparoscopy treatment is associated with a reduction in postoperative pain, systemic analgesia requirements, hospital stay, overall postoperative morbidity total hospital cost, and improved quality of life (LE 2b) [208-216].

Complicated cases of diverticular disease are classified according to the modified Hinchey classification. Stage I indicates the presence of a pericolic abscess, stage IIa indicates distant abscess amenable to percutaneous drainage, stage IIb indicates complex abscess with or without fistula, and diffuse peritonitis is classified as stage III (purulent) or stage IV (fecal) [217-219].

In Hinchey stages I and IIa, percutaneous drainage usually is effective in controlling symptoms [220], although in most cases simple medical therapy could be equally effective [221, 222]. Abscess size and location influence the likelihood of response to percutaneous therapy. In patients with septic signs after drainage and in those with Hinchey stages IIb and III, surgical treatment is indicated. In those cases, laparoscopic lavage is possible, with the aim to potentially spare the patient from a major bowel resection and stoma creation (LE 2b) [221, 222]; abundant lavage of the peritoneal cavity and positioning of multiple (at least 2) drains is indicated. The search for the perforation should not be pursued at all costs; when a large leak is automatically evident, a fecal fistula is usually present or will appear after the operation and the patient should be managed as an Hinchey IV case (LE 5) [221, 222]. However, if a small colonic perforation is found during lavage, a suture can be attempted, eventually reinforced with an omental patch. In case of a concomitant fistula with bladder and/or small bowel fistula and stenosis, lavage and drainage may allow elective management by the open or the laparoscopic approach, according to the preference of the surgeon (LE 5) [221, 222].

This strategy, which aims to convert generalized purulent peritonitis to localized diverticulitis that can be safely treated with antibiotic therapy, is successful in most cases ( $>90 \%)$, with immediate improvement of the clinical conditions of the patient, and is associated with decreased mortality and morbidity (particularly SS complications such as dehiscence, SS infection, and incisional hernia) (LE 3a) [223231]. After peritoneal lavage and drainage, elective colonic resection can be planned within 3-6 months, but some authors actually propose limiting treatment to simple peritoneal lavage and not to proceed to sigmoid resection [232]. More than $50 \%$ of patients in the reported series did not need subsequent sigmoidectomy, and the same was true for 90 of 92 cases in the Irish prospective multicenter study that followed the patients for a mean of 36 months (range $=12-84$ months) (LE 2B) [232].

Hinchey III patients in whom exploration of the abdomen is not satisfactory because of adhesions or obstruction and patients with severe peritonitis with numerous false membranes should be considered for conversion to open surgery $[223,224,226]$ or should undergo laparoscopic emergency colonic resection, but only if performed by experienced hands (LE 3b) [233-235]. Of note, elective resection of the diseased segment decreases the risk of conversion and increases the rate of primary anastomosis compared to emergency surgery (LE 5). In Hinchey stage IV, colonic resection can be performed laparoscopically or by open surgery, depending on the skill of the operator and the clinical stability of the patient, even if the evidence is still too weak for a specific recommendation (LE 3b) [215, 236, 237].

Small bowel obstruction due to adhesions

\section{Laparoscopic treatment of small bowel obstruction can be successfully accomplished in selected patients (GoR C).}

Adhesions are the leading cause of small bowel obstruction (SBO), accounting for about $75 \%$ of all SBO. The first reports of laparoscopic treatment date back to the early 1990s [238]. Surgery does not influence the risk of recurrence or the need for a future operation (LE 2b) [239, 240]. Duron et al. [241] suggested that the rate of primary or secondary recurrence (12 and $18 \%$, respectively) was not different after open compared to laparoscopic surgery (LE 2b). Neither RCTs nor prospective controlled studies on the laparoscopic approach to SBOs are available in the literature [242].

The main concern about a laparoscopic approach to SBO is the high conversion rate: complete laparoscopic treatment has been reported possible in only 50-60\% of patients. Papers published after 2005 have shown a trend toward a reduction in conversion rate in laparoscopically treated patients, consistently lower than $50 \%$ (LE 3b) [243-252].

Guidelines concerning laparoscopy and SBO published after the EAES consensus statements are controversial. The EAST guidelines for the management of bowel obstruction [253] suggest that the laparoscopic treatment of SBO can be considered and leads to a shorter hospital stay in a highly selected group of patients (LE 2). Notwithstanding, laparoscopy was not included in the suggested flowchart.

The SAGES guidelines on DL consider laparoscopy contraindicated in patients with a clear indication for surgical intervention such as massive bowel obstruction, perforated viscus (free air), and hemodynamic instability [254]. 
A systematic review that included all papers published up to 2007 (1,236 patients) found a successful therapeutic laparoscopy rate in the range of 40-88\% and a conversion rate ranging from 0 to $52 \%$. Positive predictive factors for success are fewer than two previous laparotomies and absence of peritonitis (LE 2b) [255].

Laparoscopy should not be used for diagnosis of SBO, but it should be preceded by conventional imaging in order to reduce the risk of iatrogenic injuries without therapeutic purposes. In some studies the following criteria were found to be statistically significant for failure of the laparoscopic approach: small bowel loop diameter $>4 \mathrm{~cm}$, more than two previous abdominal operations (LE 2B), operation more than $24 \mathrm{~h}$ after diagnosis, duration of surgery, and dense and extensive adhesions. Previous appendectomy was statistically associated with a higher rate of successful laparoscopic management, with the single band adhesion as the ideal condition for the laparoscopic approach (LE 3B) $[2,256-260]$.

The use of a tailored laparotomy (i.e., incision according to exploratory laparoscopy findings) would be a potential benefit of the laparoscopic approach but this has not yet been demonstrated [2, 243, 245]. Successful laparoscopic treatments of patients with negative predictive criteria are described without complication in some papers. A low threshold for conversion to traditional surgery is recommended (LE 5).

Incarcerated/strangulated hernias

Laparoscopic surgery, including TEP or TAPP repair, may be performed for the treatment of nonreducible or strangulated inguinal hernias (GoR B). The laparoscopic repair of noninguinal incarcerated hernias (diaphragmatic, either congenital or acquired, supravesical or spigelian, obturator, and internal hernias) may be performed, but further studies are necessary to validate this approach (GoR D).

In the natural history of inguinal hernia, $0.29-2.9 \%$ of cases become incarcerated, and 10-15\% of these become strangulated and gangrenous, a complication with a mortality rate of up to $5 \%$ in the elderly [261-266].

In 1993, Watson demonstrated the feasibility of laparoscopic hernia repair (LHR) for incarcerated hernias [267]. In 2003, a Cochrane library study showed that the outcome of elective LHR is at least equivalent to that of the open approach [268]. This study was confirmed in 2010 by an extensive meta-analysis [269]. On the other hand, there are no comparative studies between the laparoscopic and the open approach in emergency adult cases.

A review of cohort studies on laparoscopic repair of incarcerated groin hernias was published in 2009 by Deeba et al., updating the information given in the previous guidelines on laparoscopic emergency [2, 270]. It reviews seven articles on this topic, dating from 1989 to 2008, reporting on 328 cases treated with total extraperitoneal (TEP) or transabdominal preperitoneal (TAPP) repair. Of these seven articles, two are LE $2 b$ prospective cohort studies and five are LE 4 small case series [271-277]. The overall results of the Deeba et al. study were that average operative time was $61.3 \mathrm{~min}$, average hospital stay was 3.8 days, mortality rate was $0.28 \%$, complication rate was $10.3 \%$, conversion rate was $1.8 \%$, intestinal laparoscopic or minilaparotomy resection rate was $5.1 \%$, and reoperation rate was $0.9 \%$. The most serious complications consisted of two colonic lesions and one divided vas deferens. The others were infected mesh $(0.6 \%)$, wound infection $(0.3 \%)$, deep venous thrombosis $(0.3 \%)$, and other minor complications. The highest recurrence rate at 7 years was $5.8 \%$. The authors concluded that the laparoscopic approach, either TEP or TAPP, is possible for repairing incarcerated hernia taking into account the knowledge of anatomy and expertise needed to dissect and reduce the sac. Laparoscopy can also be used to resect bowel, if necessary, or to repair an occult contralateral hernia, present in $11.2-50 \%$ of cases. The overall complication rate, recurrence rate, and length of hospital stay seem to be very similar to those documented for open repair of strangulated/incarcerated hernias.

The "hernioscopy" is a new mixed laparoscopic-open technique for incarcerated hernias, which spontaneously reduce during the surgical manipulations. A randomized controlled study (LE 1b) suggested that this was an effective technique that involves the introduction of the laparoscope into the hernia sac to evaluate the viability of the herniated loop, thus avoiding unnecessary laparotomy [278].

There have been only a few single-case or small case series studies (LE 4) on the laparoscopic treatment of nonreducible retroxiphoid diaphragmatic hernias. They concluded that there is the need for consensus on this subject [279, 280].

Acquired diaphragmatic paraesophageal incarcerated hernias are approached by laparoscopy by some authors in low-level studies (LE 4). The most important absolute contraindication to this procedure seems to be the presence of gastric necrosis [281-284].

The mini-invasive repair of rare abdominal wall acute hernias, such as supravesical and spigelian, is rarely described. Most case reports (LE 4) concern emergency obturator hernioplasties, with good results in terms of resolution of symptoms and hospital stay [285-297].

Finally, there are several articles on the laparoscopic repair of incarcerated internal hernias such as the paraduodenal, paracecal, broad uterus ligament, transmesosigma, and iatrogenic (caused by surgical changes to the anatomy) hernias. Even though all of the studies are of low LE, the 
potential role of laparoscopy in the diagnosis seems to be demonstrated in them and would, at times, prevent unnecessary laparotomies [298-317].

\section{Ventral hernias}

The laparoscopic approach to incarcerated ventral and incisional hernias may be performed in selected patients (GoR C).

In 2005, the previous International Consensus Conference of the European Association of Endoscopic Surgery (EAES) stated that the open approach remains the standard treatment for incarcerated hernia, although laparoscopic surgery may be considered in carefully selected patients and restricted to surgeons with maximum expertise in this field (GoR C) [2].

In 2010, an Italian Consensus Conference of the main national scientific societies [Società Italiana di Chirurgia (SIC), Associazione Chirurghi Ospedalieri Italiani (ACOI), Società Italiana di Chirurgia Endoscopica (SICE), and the Italian Chapter of Hernia Society] on laparoscopic treatment of ventral and incisional hernia underlined that the incidence of intra- and postoperative complications and recurrences in emergency cases was the same as in elective cases. Good experience in emergency surgery and in laparoscopic repair of the abdominal wall in elective patients is always strictly required. The grade of recommendation was confirmed (GoR C) [318].

Patients should be selected for laparoscopic repair according to the following criteria:

- Absence of marked abdominal distension that precludes entry into the peritoneal cavity and limits adequate working space. Some studies suggested that a small bowel diameter exceeding $4 \mathrm{~cm}$, as seen on a preoperative abdominal X-ray, and a late operation $(>24 \mathrm{~h}$ after onset, $>6 \mathrm{~h}$ after hospital admission) were risk factors for conversion (LE 4) [252, 257, 319, 320].

- Some authors have introduced the number $(>4)$ of previous laparotomies as a predictive factor of conversion [319]. However, not only the number but also the type of previous procedure and the location of the surgical scars are very important. As far as adhesiolysis is concerned, one surgical xiphopubic scar following an abdominal trauma or massive peritonitis will often give rise to more difficulties than three scars (e.g., in the right subcostal area, the hypogastrium, and the right iliac region) resulting from elective and uncomplicated surgery (LE 5) [321].

- Absence of peritonitis with the need for bowel resection and bowel handling in a highly inflamed environment [322] and absence of clinical signs of intestinal ischemia (LE 4).
- Absence of high-septic-risk situations, such as concomitant execution of contaminated abdominal procedures or the presence of contaminated skin lesions or enterocutaneous fistulas (LE 4) [323].

- Absence of major defects with loss of domain or hernias that do not allow the laparoscopic approach with adequate overlap of the mesh (LE 4) [323].

- Absence of hemodynamic instability and severe comorbid conditions such as heart and lung diseases that preclude the use of pneumoperitoneum (LE 4) [322].

- Morbid obesity [324], old age, and debilitation are not considered contraindications to laparoscopy (LE 4) [321, 325].

As for operative technique, the use of atraumatic graspers is essential, adhesiolysis should be proper and cautious, and the contents in the defect should be always accurately checked for blood supply, motility, and integrity. If an enterotomy occurs, it can be repaired laparoscopically (LE 5). The mesh is positioned intraperitoneally with adequate overlap (at least $3 \mathrm{~cm}$ ); the immediate mesh repair is preferably [326-329] deferred only in cases of abundant peritoneal contamination or bowel necrosis (LE 3b) [320].

The introduction of biologic meshes in clinical practice provides a new prospective for abdominal wall defect repair in the contaminated surgical field [330]. A few authors have used biomaterial in laparoscopic emergency hernia repair, with good results in terms of recurrence and wound infection (LE 4) [331, 332]. There are no comparative trials evaluating the commercially available biologic meshes and their application in laparoscopic repair of potentially contaminated ventral hernias.

\section{Abdominal trauma}

After penetrating trauma of the abdomen, laparoscopy may be useful in hemodynamically stable patients with documented or equivocal penetration of the anterior fascia (Gor B).

Laparoscopy should be considered in hemodynamically stable blunt trauma patients with suspected intraabdominal injury and equivocal findings on imaging studies or even in patients with negative studies but with a high clinical likelihood for intra-abdominal injury ("unclear abdomen") to exclude relevant injury (GoR C).

To optimize results, the procedure should be incorporated in institutional diagnostic and treatment algorithms for trauma patients (Gor D).

Ultrasound and contrast-enhanced computed tomography (CT) can be applied quickly and efficiently in trauma patients, but hemodynamic stability is a prerequisite for a CT [333, 334]. Angiography is indicated to delineate and 
treat active bleeding of abdomen and pelvis, when detected by CT and/or other means (US or X-ray of pelvis and cystography) [334].

Diagnostic accuracy of laparoscopy has been reported as high as $75 \%$ (LE 2b) [335] and it is indicated in hemodynamically stable patients with suspected intra-abdominal lesions and equivocal findings on imaging studies, and when nonoperative management is not indicated (suspected hollow viscus injuries with peritonitis, potential diaphragmatic lesion). The procedure has been shown to effectively decrease the rate of negative laparotomies and minimize patient morbidity [336, 337]. The procedure is usually performed under general anesthesia; however, local anesthesia with intravenous sedation ("awake laparoscopy") has also been used successfully in the emergency department (LE 4) [338]. The positioning and draping of the patient should be as for trauma laparotomy so that if needed, conversion to an open technique can be accomplished without loss of time. For this reason, the patient should be supine and the entire abdomen prepared and draped from the jugular sternal notch to the groin [333]. Pneumoperitoneum should be induced slowly and carefully. If the BP drops and respiratory pressure suddenly rises, insufflation should be stopped or the gas pressure reduced [333]. The peritoneal cavity should be examined systematically, beginning with the right-upper quadrant and proceeding clockwise, taking advantage of patient-positioning manipulations. Suction/irrigation may be needed for optimal visualization, and methylene blue can be administered to help identify gastrointestinal injuries. In penetrating injuries, peritoneal violation can be determined [183]. The surgeon should not hesitate to convert to an exploratory laparotomy if he or she is not confident that there are no missed injuries (LE 4) [337].

In a highly selected group of patients, therapeutic laparoscopy should be performed only by surgeons skilled in advanced mini-invasive surgery (LE 3a) [337, 339]. Therapeutic laparoscopic options have increased in the last few years to manage hemoperitoneum, diaphragmatic, mesentery, and hollow viscus injuries and to avoid nontherapeutic laparotomy (LE 4) [340-342], and to treat perforating stab wounds of the gastrointestinal tract that can be sewn or stapled safely when laparoscopic expertise is available (LE 4) [337, 343, 344].

Procedure-related complications occur in up to $11 \%$ of patients. Tension pneumothorax in patients with diaphragmatic injury from positive-pressure pneumoperitoneum [345, 346]; gas embolism in patients with intra-abdominal venous injuries, especially in liver lacerations; and the transperitoneal absorption of carbon dioxide (which may cause metabolic and hemodynamic changes such as acidosis, cardiac suppression, atelectasis, subcutaneous emphysema, and increased intracranial pressure) might result in more profound and in some cases life-threatening consequences for the trauma patient and, as a consequence, clearly limits the potential indications for exploratory laparoscopy to a small number of very selected cases.

A retrospective cost analysis comparing the total hospital costs of exploratory laparotomy versus DL in 37 patients with penetrating abdominal trauma showed that laparoscopy is $€ 1,136$ cheaper than exploratory laparotomy [347], although in a prospective randomized study of 43 patients with abdominal stab wounds, no statistically significant difference in the total hospital costs of the two strategies was found (LE 4) [335].

Acute mesenteric ischemia

\section{Laparoscopy does not offer significant advantages in acute mesenteric ischemia besides a potential role as a bedside and second-look procedure (GoR C).}

Acute mesenteric ischemia (AMI) is an uncommon but serious disease that is often associated with other systemic illnesses and has a poor prognosis [348]. In $50 \%$ of the cases it is caused by arterial obstruction, in $20-30 \%$ by nonocclusive arterial ischemia, and in 5-15\% by venous occlusion. AMI presents a high mortality rate (59-93\%) [349] and prognosis is frequently related to the timeliness of diagnosis [350].

With a sensibility of $93.3 \%$ and a specificity of $95.9 \%$ [351], multidetector CT is the best diagnostic approach in a patient with clinical suspicion of AMI (LE 1a). Few reports have been found on the diagnostic role of laparoscopy, and literature data confirm that the laparoscopic picture of AMI depends on its stage (ischemia, infarct, and peritonitis) and etiology (arterial thrombosis and embolism, venous thrombosis, or nonocclusive mesenteric ischemia) [352]. Since laparoscopy does not offer adequate diagnostic accuracy in spite of the use of fluorescein and ultraviolet light [353, 354], it does not appear to offer advantages compared with classic imaging, although it may have a role as bedside procedure in the ICU (LE 4) [355]. There are no reports highlighting advantages of the use of laparoscopy in the treatment of patients with AMI.

The "laparoscopic second-look" might be an alternative option to the "surgical second-look" in patients already operated on for acute mesenteric ischemia (LE 4) [356, 357].

\section{Discussion}

Practice guidelines have to be regularly updated to be effective. A thorough literature review was necessary to assess whether the recommendations issued in 2006 are still current. In many cases new studies allowed us to better clarify some issues, but occasionally previous strong 
recommendations have to be challenged after review of recent research.

The accuracy of imaging techniques has enormously improved during the last few years, reducing the need to use laparoscopy as a sole diagnostic tool, thus avoiding the minimal insult of laparoscopic exploration in patients without any indication for laparoscopic treatment. On the other hand, surgical techniques have also progressed and the use of laparoscopic surgery is now widespread, increasing therapeutic laparoscopic options and allowing an even more refined diagnosis in those cases that could benefit from a laparoscopic procedure.

In the 2006, EAES consensus ventral and inguinal hernias were lumped together. In our update, we have chosen to separate the two entities as the diagnostic and therapeutic choices for each of the two conditions are substantially different. In fact, laparoscopic treatment of ventral hernias is more common than inguinal repair, and in the emergency setting their diagnosis relies on different examinations. Hernia repair has gained a grade B in emergency situations (incarcerated or strangulated), thanks to recent reviews of cohort studies reporting fair results. Interesting considerations have arisen in this field regarding hernioscopy, which is particularly useful in association with emergent open repair to assess the viability of the herniated bowel once it has fallen back into the abdominal cavity. Surgeons have gained confidence with DL over the last few years, and even if accuracy of the imaging techniques have improved at the same time, laparoscopy appears to be particularly useful when a laparoscopic treatment is also possible, as for NSAP, gynecological pathology, and SBO. On the other hand, the available imaging techniques reduce the indications for laparoscopy in mesenteric ischemia to only its bedside application and second-look operations. Some progress has also been seen in the treatment of acute cholecystitis, for which complicated disease (gangrenous or empyemic) or age is no longer considered a contraindication for laparoscopic emergency treatment (GoR B). Moreover, laparoscopic cholecystectomy is feasible and has its place also in high-risk patients as an alternative to percutaneous cholecystostomy or to conservative treatment, and it has comparable results. Early cholecystectomy seems to have substantial advantages in the acute setting. Early (same admission) laparoscopic cholecystectomy is still advised after biliary pancreatitis, and interesting applications of retroperitoneoscopy are starting to gain evidence in the step-up approach to necrotic infections. Laparoscopic lavage and drainage in the treatment of Hinchey II-III diverticulitis has gained wider application. The role of laparoscopy in trauma is still limited to stable patients, essentially to ascertain whether there has been peritoneal violation or for a diagnosis in "unclear abdomen" as a consequence of an equivocal diagnostic workup.
Some of the RCTs and reviews published in the last 5 years have raised some concerns about laparoscopy when compared to standard open treatments in some cases. This was the case for laparoscopic PPU repair, in which morbidity due to suture leakage seems higher with laparoscopic repair. The panel agreed that the good outcomes experienced in everyday practice of laparoscopic PPU repair have not been reflected in the available literature studies. Some reappraisal has been made for laparoscopic appendectomy, which remains strongly recommended in fertile women, even if the advantages for men, the obese, the elderly, and pregnant women might be minor. An effort to establish the right treatment recommendations for a normal appendix found at laparoscopy has been made.

The technique of pneumoperitoneum induction and the surgical learning curve, both topics of general interest for the laparoscopic surgeon, have been widely discussed.

In regard to establishing pneumoperitoneum in the emergency setting, the panel has not converged on an opinion on the best single technique. This is due to the different preferences and practices of individual surgeons and the lack of evidence in the literature to favor a specific access mode (closed or open). Each access modality has its specific complications and there is no clear evidence to suggest which is the best method for the individual patient's problem (bowel distension, previous laparotomies, and so on). The surgeon's experience in using his chosen method is very important.

The panel agreed that the use of laparoscopy in an emergency setting requires surgical experience and skills; however, in the literature there is no complete and objective definition of "experienced" and "skilled" and several factors limit our ability to reach such definitions. A specific "learning curve" for every single situation is impossible to define, particularly in an emergency laparoscopic setting where the operative condition may be worsened by reduction of the surgical field (intestinal distension, adhesions), unclear anatomy due to the inflammatory status, and a wide variety of possible therapeutic findings. On the other hand, there was a general agreement that experience gained in one specific procedure reduces the learning curve for other procedures because the judgment, ability, and skills developed can be used in a large number of situations.

Every surgeon has to decide the best approach to use according to his or her own experience, the particular clinical situation, his/her proficiency (and the experience of the team) with the various techniques and the specific organizational setting in which he/she is working. A low threshold for conversion carries only minor disadvantages for the patient, and such good judgment can obviate the need for a questionable strict definition of "expert laparoscopic emergency surgeon." These guidelines have been 
developed to help surgeons with their decisions in the very difficult situation of emergency surgery.

\section{Annex: Anesthesia in laparoscopic surgery for abdominal emergencies: anesthetic considerations}

Anna Levati and Domenico Pietrini for the Società Italiana di Anestesia Analgesia Rianimazione e Terapia Intensiva (SIAARTI) (Italian Society of Anaesthesia, Analgesia, Resuscitation and Intensive Care)

The overall incidence of perioperative complications depends on several multidisciplinary factors. Patient physical status according to the American Society of Anesthesiologists (ASA) classification, emergency or routine interventions, intraoperative determinants (bleeding, long operating time), and the clinical experience of care-givers (mainly anesthesiologists and surgeons). All these factors can significantly affect the postoperative course (LE 2b) [358].

The literature data regarding laparoscopy-related complications and mortality rate are few and show conflicting results. Bottger et al. [358] describes an overall postoperative hospital mortality rate of $2.6 \%$, with cardiac or pulmonary complications predominating. A significant mortality rate $(10 \%)$ is associated with emergency surgery, while elective surgery has by a lower rate $(2 \%)$.

General complications (up to $12 \%$ of the treated patients according to Bottger data) are cardiac impairment, protracted ventilation, cerebral complications, reanimation, pneumonia, and urinary tract infection. Surgical site infection, anastomotic leakage, bleeding, and sepsis represent mainly surgical complications. A significant correlation has been reported between cardiac complication and the need for protracted ventilation with ASA patient physical status, operative time, and requirement for blood transfusion. A close correlation between the anesthesiologist's skill and perioperative complications has been also described (LE 2b) [358].

Total operative time has been reported to be significantly affected in patients with incarcerated hernia contents preoperatively, suprapubic hernia location, bowel adhesion to the abdominal wall or hernia sac, a greater number of previous ventral hernia repairs, and larger hernia defects. Total operative time may be also affected by a higher ASA classification and hernias requiring a larger mesh for repair (LE 2b) [359]. During laparoscopy, pneumoperitoneum (PP) may result in intraoperative atelectasis. Positive end expiratory pressure (PEEP) of $5 \mathrm{cmH}_{2} \mathrm{O}$ in pressure-controlled ventilation (PCV) mode has been suggested by Ji et al. [360] to protect pulmonary gas exchange during surgery (LE 2b).

Conversely, Luz-Moreira et al. [361] found that laparoscopic colectomy (LC) could be a safe option for patients with a high ASA classification as the LC approach is associated with faster postoperative recovery, lower morbidity rates, and lower hospital costs than the open colectomy (OC) approach (LE 2b). Luz-Moreira et al. reported an overall morbidity rate of $24 \%$ with an overall postoperative morbidity and wound infection rate significantly lower in the LC group than in the OC group and no difference in 30-day reinterventions or postoperative mortality between the two groups. Interestingly, the LC group also had significantly less estimated blood loss. LuzMoreira et al. concluded that LC should be considered safe for ASA 3 and 4 patients and is associated with faster postoperative recovery, lower morbidity, and similar hospital costs compared with OC.

The literature did not systematically report pulmonary complications, and most studies did not have sufficient statistical power to detect differences in postoperative pulmonary complication rates (LE 2a) [362] so it is not clear whether laparoscopic procedures reduce the risk for clinically important pulmonary complications.

A detailed multidisciplinary strategy has been described by Patel et al. [363] to facilitate early recovery (LE 4). In patients undergoing a laparoscopic procedure, antibiotics administration is planned prior to surgery, followed by 8-10 mg dexamethasone at induction of anesthesia. The surgical approach is performed with no use of drains and tubes, use of a urinary catheter (for right and transverse colon resections), and immediate removal of the catheter after low anterior colon resections. Epidural anesthesia is also avoided. However, the anesthetic technique should be tailored to the type of surgery. General anesthesia (balanced anesthesia technique with several intravenous and inhalational agents and the use of muscle relaxants), peripheral nerve blocks, and neuraxial anesthesia as an alternative to general anesthesia for outpatient pelvic laparoscopy, local anesthesia infiltration in microlaparoscopy for limited and precise gynecological procedures, and intravenous sedation can be used with a safe profile for patients and have been described in the literature (LE 5) [364], (LE 4) [365], (LE 2b) [366, 367], (LE 1b) [368], (LE 1a) [369], (LE 4) [370], (LE 1b) [371, 372], (LE 2b) [373, 374], (LE 1b) [375]. Laparoscopy is most commonly performed with the patient under general anesthesia, especially for prolonged and upper abdominal procedures. However, regional techniques involving peripheral and neuraxial blocks and local anesthetic infiltrations could be used for pelvic laparoscopy. Finally, spinal and epidural anesthesia and the combination of the two have been described as suitable for pelvic laparoscopy.

Standardization of the surgical technique, resulting in reduced surgical time and "bloodless", surgery, standardization of intraoperative monitoring, and use of skilled anesthesiologists for high-risk patients may partially modify the rate of perioperative complications, but other 
factors such as obesity, ASA classification, and urgency of the intervention cannot be influenced by clinicians.

\section{Suggestions}

The patient should be evaluated by the whole team (surgeon, anesthetist, and radiologist) with the aim to define risk/benefit ratio.

\section{Patient eligibility for laparoscopic procedures}

Preoperatively, the patients should undergo a comprehensive physical examination, followed by further investigations (laboratory and instrumental diagnostic evaluations such as electrocardiogram, plain chest X-ray, internist workup consultation) and given an ASA score in order to properly plan the management of anesthesia. Prior to surgery, according to EAES guidelines (LE 1b) [376], a patient scheduled for laparoscopic surgery should be evaluated regarding the presence of comorbidities, assessment of ASA III-IV, COPD, NYHA III-IV, and chronic renal failure (CRF). The presence of heart disease should not constitute an absolute contraindication to laparoscopic surgery (LE 2b) [377] since perioperative risks can be reduced by adopting the most appropriate anesthesia and/or surgical treatment option. In trauma patients a minimally invasive approach could be useful and safe as it can reduce the potential morbidity of negative laparotomy (LE 3a) [378].

\section{Suggestions}

Stability of hemodynamic and respiratory parameters is necessary to perform laparoscopic procedures. Major trauma patients or patients with severe disease may be eligible if lasting stability of hemodynamic and respiratory parameters is achieved after resuscitation and/or intensive medical treatment.

\section{Pathophysiological changes during laparoscopy}

In laparoscopic surgery, $\mathrm{PP}$ is the crucial element that affects respiratory mechanisms and cardiovascular responses, especially in patients with comorbidities. The knowledge of pathophysiological changes is essential in order to plan an appropriate anesthesia strategy aimed at early detection and prevention of potential complications.

\section{Respiratory effects}

PP, which shifts the diaphragm upward, decreases lung compliance that leads to a diminished functional residual capacity. Even if uncommon in healthy patients (LE 1b) [379], a ventilation-perfusion mismatch may also occur, sometimes resulting in perioperative hypoxemia (LE 1b) [380-382]; (LE 2a) [383]. A decrease in lung volume associated with airway $\left(\mathrm{P}_{\mathrm{aw}}\right)$ and intra-abdominal pressure (IAP) increases may lead to lung atelectasis, mainly in patients with extensive pulmonary disease (LE 1b) [364, 376]. An IAP higher than $15 \mathrm{mmHg}$ associated with the Trendelenburg position should be avoided because it may severely reduce pulmonary compliance causing a ventilation-perfusion mismatch (LE 1b) [384].

Transperitoneal $\mathrm{CO}_{2}$ absorption determines higher endtidal $\mathrm{CO}_{2}\left(\mathrm{EtCO}_{2}\right)$ 8-10 min after gas insufflation, irrespective of the site and duration of administration; increased minute ventilation maintains $\mathrm{PaCO}_{2}$ in normal limits in most cases, possibly leading to a further increase in airway pressure (LE 1b) $[385,386]$. Increased arterial $\mathrm{CO}_{2}$ content might not be accurately reflected by $\mathrm{EtCO}_{2}$, perhaps as a consequence of increased dead space induced by PP.

\section{Cardiovascular effects}

Major hemodynamic alterations include hypotension, hypertension, arrhythmias, and cardiac arrest; the cardiovascular effects of $\mathrm{PP}$ occur during gas insufflation and are associated with IAP levels, the volume of $\mathrm{CO}_{2}$ absorbed, and the patient's intravascular volume, comorbidities, and positioning, with IAP and patient positioning being the most important determinants of cardiovascular function during laparoscopy (LE 1b).

Abdominal venous compression causes a decline in venous return and preload due to a reduced flow through the inferior vena cava (LE 1b) [384, 387]; IAP and the stimulated neurohormonal vasoactive system cause an increase in mean arterial pressure, systemic vascular resistance (SVR), and pulmonary vascular resistance (PVR), resulting in an increased afterload (LE 1b) [388].

Preload and afterload combined variations may cause a decrease in cardiac output (CO), with a further detrimental effect following head-up positioning and inadequate intravascular volume content (LE 1b) [389].

Although venous return decreases during PP, central venous pressure (CVP) and pulmonary capillary wedge pressure (PCWP) rise during abdominal insufflations, probably because of a cephalic shift of diaphragm with increased intra-abdominal and intrathoracic pressure. In ASA I and II patients, hemodynamic changes at an IAP level lower than $15 \mathrm{mmHg}$ are not clinically relevant and vanish after desufflation (LE 1b) [376].

Regional perfusion (brain, kidney, liver, and bowel) may also be affected by the rise of IAP (LE 1b) [390]; these changes should especially be considered in patients with 
impaired hepatic and/or renal function or modified cerebral hemodynamics (LE 5) [391]. According to previous data, the IAP level should be as low as possible in critically ill patients undergoing laparoscopic surgery for abdominal urgencies.

\section{Monitoring during anesthesia}

While under anesthesia, standard and comprehensive monitoring (HR, ECG, $\mathrm{BP}, \mathrm{SpO}_{2}, \mathrm{EtCO}_{2}, \mathrm{P}_{\mathrm{aw}}$, and body temperature) should be applied to enrolled patients. Airway pressures, both peak and plateau pressures, should be monitored during the entire procedure; it is necessary to closely monitor $\mathrm{P}_{\mathrm{aw}}$ at the time of induction of PP with the aim of adjusting the $\mathrm{P}_{\mathrm{aw}}$ to a new acceptable value if necessary. Monitoring the changes of airway pressures during PP enables the early detection of atelectasis (LE 5) [392].

Even if $\mathrm{EtCO}_{2}$ does not accurately reflect $\mathrm{PaCO}_{2}$ changes, it should be used to indirectly assess an increase in arterial $\mathrm{CO}_{2}$ and to titrate minute ventilation with the aim of correcting increased plasma $\mathrm{CO}_{2}$ concentrations (LE 1b) [376]. In patients with compromised cardiopulmonary function, frequent arterial blood gas analysis may be necessary as the $\mathrm{PaCO}_{2} / \mathrm{EtCO}_{2}$ gradient ( $\mathrm{LE} 1 \mathrm{~b}$ ) may change; therefore, an arterial line positioning is suggested in ASA III and IV patients.

An increase in CVP following PP institution may lead to possible misinterpretation of preload status. As for airway pressure, measurement before and after PP application makes it possible to detect hemodynamic changes and properly assess the true patient volemia. In ASA III and IV patients, invasive monitoring of arterial BP and of circulating volume is strongly suggested (LE 1b) [379].

\section{Suggestions}

Standard monitoring (HR, ECG, BP, $\mathrm{SpO}_{2}, \mathrm{EtCO}_{2}, \mathrm{P}_{\mathrm{aw}}$, body temperature) for general anesthesia should be performed. Invasive arterial BP and circulating volume monitoring is strongly suggested in ASA III and IV patients.

\section{Ventilatory strategies to protect the lung}

A rational approach to overcome the increase in $\mathrm{PaCO}_{2}$ and acidosis is controlled mechanical hyperventilation (LE 1b) [385]. As a detriment, ventilator-induced lung injury (VILI) is closely related to high-volume/high-pressure mechanical ventilation mode, especially during long procedures; therefore, a reduction in $\mathrm{PaCO}_{2}$ should be achieved through a greater respiratory rate thus avoiding tidal volume increase.
PEEP is a rational strategy for keeping the lungs open and preventing lung injury and atelectasis (LE 5) [392]. In fact, the use of PEEP increases alveolar recruitment, especially in patients at greater risk of atelectasis (obese patients and those with underlying lung disease) (LE 1b) [393]. In case of atelectasis, hypoxemia can develop when the patient is under anesthesia and in the postoperative period. The first-line treatment is to increase the inspiratory fraction of oxygen $\left(\mathrm{FiO}_{2}\right)$, keeping in mind that oxygen toxicity might injure the lung.

There is no evidence to suggest that PCV is better than volume-controlled ventilation to prevent lung injury and improve oxygenation during laparoscopic surgery, even if "peak pressure " is limited with PCV (LE 1b) [394, 395].

\section{Suggestions}

In order to improve patient oxygenation, increasing the respiratory rate is safer than higher tidal volume. Positive end-expiratory pressure (PEEP) is suitable to "open up the lung and keep it open." Recruitment maneuvers are useful in recruiting the collapsed alveoli.

\section{Nonventilatory strategies to protect the lung: positioning and anesthesia}

The reverse Trendelenburg position improves respiratory mechanisms and oxygenation, while the Trendelenburg position worsens lung compliance during PP (LE 3b) [396]. In a recent review, Valenza et al. (LE 5) [392] reported that head-up positioning alone or PEEP in the supine position each has the same effect on lung volume and oxygenation, while $\mathrm{P}_{\mathrm{aw}}$ is lower when the patient is in the beach-chair position. However, Valenza et al. prefer head-up positioning, if appropriate, to protect the lung. In the case of the Trendelenburg position, close monitoring of $\mathrm{P}_{\mathrm{aw}}$ is mandatory to titrate the mechanical ventilation parameters so as to prevent lung strain and atelectasis formation.

At the moment, there are no available data to make either inhalational or intravenous anesthesia preferable for laparoscopy. However, in 1998, Gehring et al. [397] found $\mathrm{PaCO}_{2}$ levels to be significantly higher and $\mathrm{PaO}_{2}$ concentrations significantly lower in patients undergoing isoflurane anesthesia than in patients undergoing propofol anesthesia (LE 1b).

\section{Suggestions}

The reverse Trendelenburg position is associated with an improvement of lung compliance and a decrease of $\mathrm{P}_{\mathrm{aw}}$. With the Trendelenburg position, it is mandatory to strictly monitor the $\mathrm{P}_{\mathrm{aw}}$ in order to titrate the mechanical 
ventilation parameters so as to prevent lung strain and atelectasis formation.

\section{Anesthesia and laparoscopic surgery in obese patients}

The obese patient is generally evaluated as a complicated patient. Merkow et al. [398] found an adverse correlation between body mass index (BMI) and short-term outcomes in cancer patients undergoing open colectomy. The morbidly obese group was found to have a higher morbidity rate than normal-weight patients, particularly with respect to such complications as wound infection, dehiscence, pulmonary embolism, and renal failure (LE 1a) [398]. At the same time, Scheidbach et al. [399] evaluated laparoscopic colorectal resection in overweight, obese, and morbidly obese patients and reported equivalent outcomes for these groups; however, no extensive investigation of the correlation between the degree of BMI, the feasibility of laparoscopic colon resection, the benefits, and the shortterm outcomes was provided (LE 1a) [399]. Respiratory function is markedly impaired in morbidly obese patients (BMI $\geq 40 \mathrm{~kg} / \mathrm{m}^{2}$ ) undergoing laparoscopic surgery. Several factors contribute to this effect on pulmonary function: supine position, muscle paralysis, and PP (LE 2b) [400, 401]. The related reduced functional residual capacity, increased closing volume, and consequent atelectasis (LE 3a) $[402,403]$ increase the risk for postoperative respiratory complications (LE 1b) [404] and prolonged length of hospital stay (LE 1b) [405]. Almarakbi et al. [393] found that recruitment with the inspiratory maneuver repeated every $10 \mathrm{~min}$ followed by application of PEEP at 10 $\mathrm{cmH}_{2} \mathrm{O}$ was associated with the best intraoperative respiratory compliance, i.e., a $\mathrm{PaCO}_{2}$ decrease and a $\mathrm{PaO}_{2}$ increase in obese patients undergoing laparoscopic gastric banding without adverse events (LE 1b) [395].

Intraoperative ventilatory strategies should be adopted to improve gas exchange and prevent VILI. If these strategies are followed, laparoscopic procedures may be performed even in morbidly obese patients, with clinical outcomes (recovery of intestinal function and LOS) equivalent to those for nonobese patients. However, the complication rate (morbidity and conversion rates) is higher for morbidly obese patients undergoing LC than for nonobese patients.

\section{Suggestions}

The morbidly obese patient has a higher morbidity rate than a normal-weight patient. As the most frequent complications are respiratory, intraoperative ventilatory strategies should be adopted to improve gas exchange and prevent VILI.

\section{Anesthesia and laparoscopic surgery in pregnant patients}

According to some evidence in the literature, laparoscopic surgery in pregnancy seems to be a safe option. The most common indications are cholelithiasis, appendicitis, persistent ovarian cyst, AT (LE 5) [406, 407], splenectomy (LE 4) [408], heterotopic pregnancies, and adrenal pheochromocytoma (LE 4) [409]. Interestingly Sagiv et al. [410] reported a significant number of successful cases of laparoscopicsurgery for extrauterine pregnancy in hemodynamically unstable patients (LE 2b) [410]. However, changes in respiratory and cardiovascular function may be present: adding PP to an abdomen during pregnancy is generally associated with a significant increase in peak airway pressure, a decrease in functional reserve capacity, increased pulmonary shunt, increased alveolar-arterial oxygen gradient, and decreased respiratory compliance (LE 4) [411]. As a consequence, anesthesiologists should pay special attention to patient positioning during surgery and to the physiological and mechanical effects following $\mathrm{CO}_{2}$ $\mathrm{PP}$ realization.

$\mathrm{CO}_{2}$ and fetal heart monitoring and prophylaxis for deep vein thrombosis should be performed during laparoscopic procedures. End-tidal carbon dioxide and maternal BP should be respectively maintained at $32-34 \mathrm{mmHg}$ and within $20 \%$ of baseline values. Finally, abdominal insufflation pressure of carbon dioxide should not rise above 12-15 mmHg (LE 5) [412]. The Society of American Gastrointestinal Endoscopic Surgeons (SAGES) published guidelines for laparoscopic surgery during pregnancy that include perioperative monitoring of arterial blood gases as well as perioperative fetal and uterine monitoring, reinforced in a practice guideline in 2000 . However, anesthesia management for pregnant women undergoing laparoscopic surgery does not differ from anesthesia during pregnancy for any other procedure (LE 5) [413].

\section{Suggestions}

Changes in respiratory and cardiovascular function may be observed in pregnant women: adding PP to an abdomen may lead to a significant increase in peak airway pressure, decrease in functional reserve and capacity, increased pulmonary shunt, increased alveolar-arterial oxygen gradient, and decreased respiratory compliance. As a consequence, special attention should be paid to patient positioning during surgery and to the physiological and mechanical effects following $\mathrm{CO}_{2}$ pneumoperitoneum realization.

Acknowledgements The authors thank Mrs. Janette Hanney from the UK for the linguistic review of the manuscript, and Mr. Giorgio 
Scaramuzza for the Cittadinanzattiva (Citizenship), and Doctor A. L. Del Favero, CEO ULSS7 della Regione Veneto, Pieve di Soligo (TV), for the Federsanità (Italian Federation of Local Health District and Municipalities), for their active presence and contribution to this Consensus. Scientific Committee of the Consensus: F. Agresta (promoter and organizer), G. L. Baiocchi, A. Corradi, E. Lettieri (Health Technology expert), M. Lupo, G. Pernazza. Experts Panel: L. Ansaloni, C. Bergamini, F. C. Campanile, M. Carlucci, G. Cocorullo, B. Franzato, V. Mandalà, A. Mirabella, M. Piccoli, C. Staudacher, N. Vettoretto, M. Zago. Representatives: M. Rasi for the IPASVI (Italian National Federation Nursing Council); S. De Masi for the ISS (Italian Health Institute); A. Levati and D. Pietrini, for the SIAARTI (Italian Society of Anesthesia, Analgesia, Resuscitation and Intensive Care); Giuseppe De Placido, President of the SEGI (Italian Society of Gynecological Endoscopy) on behalf of SIGO (Italian Society of Obstetrics and Gynaecology); M. Francucci for the SIMM (Italian Hospital Managers Society); M. Scaglione for the SIRM (Italian Society of Radiology); A. L. Del Favero for the Federsanità (Italian Federation of Local Health Districts and Municipalities); G. Scaramuzza for Cittadinanzattiva (Citizenship). Reviewers: A. Fingerhut and S. Uranüs for the EAES and S. Garattini Istituto Mario NegriItalian Cochrane Center.

Disclosures Drs. Ferdinando Agresta, Luca Ansaloni, Gian Luca Baiocchi, Carlo Bergamini, Fabio Cesare Campanile, Michele Carlucci, Giafranco Cocorullo, Alessio Corradi, Boris Franzato, Massimo Lupo, Vincenzo Mandalà, Antonino Mirabella, Graziano Pernazza, Micaela Piccoli, Carlo Staudacher, Nereo Vettoretto, Mauro Zago, Emanuele Lettieri, Anna Levati, Domenico Pietrini, Mariano Scaglione, Salvatore De Masi, Giuseppe De Placido, Marsilio Francucci, Monica Rasi, Abe Fingerhut, Selman Uranüs, and Silvio Garattini have no conflicts of interest or financial ties to disclose.

\section{References}

1. Grundmann RT, Petersen M, Lippert H, Meyer F (2010) Das acute (chirurghische) abdomen-epidemiologie, diagnostik und allgemeine prinzipien des managements. Z Gastroenterol 48:696-706

2. Sauerland S, Agresta F, Bergamaschi R, Borzellino G, Budzynsky A, Champault G, Fingerhut A, Isla A, Johansson M, Lundorff P, Navez B, Saad S, Neugebauer EA (2006) Laparoscopy for abdominal emergencies: evidence based guidelines of the European Association for Endoscopic Surgery. Surg Endosc 20(1):14-29

3. Eccles M, Mason J (2001) How to develop cost-conscious guidelines. Health Technol Assess 5(16):1-69

4. Scottish Intercollegiate Guidelines Network (2008) SIGN 50: a guideline developer's handbook, rev. edn. http://www.sign.ac.uk/ guidelines/fulltext/50/index.html

5. National Guidelines System (SNLG), Italian National Institute of Health (ISS) (2009) www.snlg-iss.it

6. Hirota M, Takada T, Kawarada Y, Nimura Y, Miura F, Hirata K, Mayumi T, Yoshida M, Strasberg S, Pitt H, Gadacz TR, de Santibanes E, Gouma DJ, Solomkin JS, Belghiti J, Neuhaus H, Büchler MW, Fan ST, Ker CG, Padbury RT, Liau KH, Hilvano SC, Belli G, Windsor JA, Dervenis C (2007) Diagnostic criteria and severity assessment of acute cholecystitis: Tokyo Guidelines. J Hepatobiliary Pancreat Surg 14(1):78-82

7. Kiviluoto T, Siren J, Luukkonen P, Kivilaakso E (1998) Randomised trial of laparoscopic versus open cholecystectomy for acute and gangrenous cholecystitis. Lancet 351:321-325
8. Johansson M, Thune A, Nelvin L, Stiernstam M, Westman B, Lundell L (2005) Randomized clinical trial of open versus laparoscopic cholecystectomy in the treatment of acute cholecystitis. Br J Surg 92:44-49

9. Csikesz N, Ricciardi R, Tseng JF, Shah SA (2008) Current status of surgical management of acute cholecystitis in the United States. World J Surg 32(10):2230-2236

10. Boo YJ, Kim WB, Kim J, Song TJ, Choi SY, Kim YC, Suh SO (2007) Systemic immune response after open versus laparoscopic cholecystectomy in acute cholecystitis: a prospective randomized study. Scand J Clin Lab Invest 67(2):207-214

11. Schietroma M, Carlei F, Cappelli S, Pescosolido A, Lygidakis NJ, Amicucci G (2007) Effects of cholecystectomy (laparoscopic versus open) on PMN-elastase. Hepatogastroenterology 54(74):342-345

12. Borzellino G, Sauerland S, Minicozzi AM, Verlato G, Di Pietrantonj C, de Manzoni G, Cordiano C (2008) Laparoscopic cholecystectomy for severe acute cholecystitis. A meta-analysis of results. Surg Endosc 22(1):8-15

13. Soleimani M, Mehrabi A, Mood ZA, Fonouni H, Kashfi A, Büchler MW, Schmidt J (2007) Partial cholecystectomy as a safe and viable option in the emergency treatment of complex acute cholecystitis: a case series and review of the literature. Am Surg 73(5):498-507

14. Fried GM, Barkun JS, Sigman HH, Joseph L, Clas D, Garzon J, Hinchey EJ, Meakins JL (1994) Factors determining conversion to laparotomy in patients undergoing laparoscopic cholecystectomy. Am J Surg 167:35-41

15. Brunt LM, Quasebarth MA, Dunnegan DL, Soper NJ (2001) Outcomes analysis of laparoscopic cholecystectomy in the extremely elderly. Surg Endosc 15:700-705

16. Bingener J, Richards ML, Schwesinger WH, Strodel WE, Sirinele KR (2003) Laparoscopic cholecystectomy for elderly patients; gold standard for golden years? Arch Surg 138:531-535

17. Kirshtein B, Bayme M, Bolotin A, Mizrahi S, Lantsberg L (2008) Laparoscopic cholecystectomy for acute cholecystitis in the elderly: is it safe? Surg Laparosc Endosc Percutan Tech 18:334-339

18. do Amaral PC, Azaro Filho Ede M, Galvao TD et al (2006) Laparoscopic cholecystectomy for acute cholecystitis in elderly patients. JSLS 10:479-483

19. Pessaux P, Regenet N, Tuech JJ, Rouge C, Bergamaschi R, Arnaud JP (2001) Laparoscopic versus open cholecystectomy: a prospective comparative study in the elderly with acute cholecystitis. Surg Laparosc Endosc Percutan Tech 11(4):252-255

20. Lujan JA, Sanchez-Bueno F, Parrilla P, Robles R, Torralba JA, Gonzalez-Costea R (1998) Laparoscopic vs. open cholecystectomy in patients aged 65 and older. Surg Laparosc Endosc Percutan Tech 8(3):208-210

21. Chau CH, Tang CN, Siu WT, Ha JP, Li MK (2002) Laparoscopic cholecystectomy versus open cholecystectomy in elderly patients with acute cholecystitis: retrospective study. Hong Kong Med J 8:394-399

22. Massie MT, Massie LB, Marrangoni AG, D’Amico FJ, Sell HW (1993) Advantages of laparoscopic cholecystectomy in the elderly and in patients with high ASA classifications. J Laparoendosc Surg 3:467-476

23. Van der Linden W, Edlund G (1970) Early versus delayed operation for acute cholecystitis. A controlled clinical trial. Am J Surg 120:7-13

24. Lathinen J, Alhava EM, Aukee S (1978) Acute cholecystitis treated by early and delayed surgery. A controlled clinical trial. Scand J Gastroenterol 13:673-678

25. Jarvinen HJ, Hastbacka J (1980) Early cholecystectomy for acute cholecystitis: a prospective randomized study. Ann Surg 191:501-505 
26. Norrby S, Herlin P, Holmin T, Sjodahl R, Tegesson C (1983) Early or delayed cholecystectomy in acute cholecystitis? A clinical trial. Br J Surg 70:163-165

27. Kum CK, Goh PM, Isaac JR, Tekant Y, Ngoi SS (1994) Laparoscopic cholecystectomy for acute cholecystitis. Br J Surg 81:1651-1654

28. Kum CK, Eypasch E, Lefering R, Math D, Paul A, Neugebauer E, Troidl H (1996) Laparoscopic cholecystectomy for acute cholcystitis: is it really safe? World J Surg 20:43-49

29. Lai PBS, Kwong KH, Leung KL, Kwok SPY, Chan ACW, Chung SCS, Lau WY (1998) Randomized trial of early versus delayed laparoscopic cholecystectomy for acute cholecystitis. $\mathrm{Br}$ J Surg 85(6):764-767

30. Lo C, Liu C, Fan S, Lai ECS, Wong J (1998) Prospective randomized study of early versus delayed laparoscopic cholecystectomy for acute cholecystitis. Ann Surg 227(4):461-467

31. Dàvila D, Manzanares C, Pichò ML, Albors P, Càrdenas F, Fuster E (1999) Experience in the treatment (early vs delayed) of acute cholecystitis via laparoscopy. Cir Esp 66(suppl 1):233

32. Chandler CF, Lane JS, Ferguson P, Thompson JE, Ashley SW (2000) Prospective evaluation of early versus delayed laparoscopic cholecystectomy for treatment of acute cholecystitis. Am Surg 66:896-900

33. Johansson $\mathrm{M}$, Thune A, Blomqvist A, Nelvin L, Lundell L (2003) Management of acute cholecystitis in the laparoscopic era: results of a prospective, randomized clinical trial. J Gastrointest Surg 7:642-645

34. Serralta AS, Bueno JL, Planells MR, Rodero DR (2003) Prospective evaluation of emergency versus delayed laparoscopic cholecystectomy for early cholecystitis. Surg Laparosc Endosc Percutan Tech 13:71-75

35. Kolla SB, Aggarwal S, Kumar A, Kumar R, Chumber S, Parshad R, Seenu V (2004) Early versus delayed laparoscopic cholecystectomy for acute cholecystitis: a prospective randomized trial. Surg Endosc 18:1323-1327

36. Papi C, Catarci M, D’Ambrosio L, Gili L, Koch M, Grassi GB, Capurso L (2004) Timing of cholecystectomy for acute calculous cholecystitis: a meta-analysis. Am J Gastroenterol 99: $147-155$

37. Shikata S, Noguchi Y, Fukui T (2005) Early versus delayed cholecystectomy for acutecholecystitis: a meta-analysis of randomized controlled trials. Surg Today 35:553-560

38. Lau H, Lo Y, Patil NG, Yuen WK (2006) Early versus delayedinterval laparoscopic cholecystectomy for acute cholecystitis: a metaanalysis. Surg Endosc 20:82-87

39. Gurusamy KS, Samraj K (2006) Early versus delayed laparoscopic cholecystectomy for acute cholecystitis. Cochrane Database Syst Rev (4):CD005440

40. Siddiqui T, MacDonald A, Chong PS, Jenkins JT (2008) Early versus delayed laparoscopic cholecystectomy for acute cholecystitis: a meta-analysis of randomized clinical trials. Am J Surg 195(1):40-47

41. Gurusamy K, Samraj K, Gluud C, Wilson E, Davidson BR (2010) Meta-analysis of randomized controlled trials on the safety and effectiveness of early versus delayed laparoscopic cholecystectomy for acute cholecystitis. Br J Surg 97(2): $141-150$

42. Yadav RP, Adhikary S, Agrawal CS, Bhattarai B, Gupta RK, Ghimire A (2009) Kathmandu Univ Med J (KUMJ) 7(25):16-20

43. Sánchez Beorlegui J, Lagunas Lostao E, Lamata Hernández F, Monsalve Laguna EC (2009) Treatment of acute cholecystitis in the elderly: urgent surgery versus medical therapy and surgery delay. Rev Gastroenterol Peru 29(4):332-340

44. Riall TS, Zhang D, Townsend CM Jr, Kuo YF, Goodwin JS (2010) Failure to perform cholecystectomy for acute cholecystitis in elderly patients is associated with increased morbidity, mortality, and cost. J Am Coll Surg 210(5):668-679

45. Vetrhus M, Søreide O, Nesvik I, Sondenaa K (2003) Acute cholecystitis: delayed surgery or observation. A randomized clinical trial. Scand J Gastroenterol 38:985-990

46. Akyürek N, Salman B, Yüksel O, Tezcaner T, Irkörücü O, Yücel C, Oktar S, Tatlicioğlu E (2005) Management of acute calculous cholecystitis in high-risk patients: percutaneous cholecystotomy followed by early laparoscopic cholecystectomy. Surg Laparosc Endosc Percutan Tech 15(6):315-320

47. Macrì A, Scuderi G, Saladino E, Trimarchi G, Terranova M, Versaci A, Famulari C (2006) Acute gallstone cholecystitis in the elderly: treatment with emergency ultrasonographic percutaneous cholecystostomy and interval laparoscopic cholecystectomy. Surg Endosc 20(1):88-91

48. Borzellino G, de Manzoni G, Ricci F, Castaldini G, Guglielmi A, Cordiano C (1999) Emergency cholecystostomy and subsequent cholecystectomy for acute gallstone cholecystitis in the elderly. Br J Surg 86(12):1521-1525

49. Kim HJ, Lee SK, Kim MH, Yoo KS, Lim BC, Seo DW, Min YI (2000) Safety and usefulness of percutaneous transhepatic cholecystoscopy examination in high-risk surgical patients with acute cholecystitis. Gastrointest Endosc 52(5):645-649

50. Winbladh A, Gullstrand P, Svanvik J, Sandström P (2009) Systematic review of cholecystostomy as a treatment option in acute cholecystitis. HPB (Oxford) 11(3):183-193

51. Macafee DA, Humes DJ, Bouliotis G, Beckingham IJ, Whynes DK, Lobo DN (2009) Prospective randomized trial using costutility analysis of early versus delayed laparoscopic cholecystectomy for acute gallbladder disease. $\mathrm{Br} \mathrm{J}$ Surg 96(9): $1031-1040$

52. Wilson E, Gurusamy K, Gluud C, Davidson BR (2010) Costutility and value-of-information analysis of early versus delayed laparoscopic cholecystectomy for acute cholecystitis. Br J Surg 97(2):210-219

53. Flum DR, Dellinger EP, Cheadle A, Chan L, Koepsell T (2003) Intraoperative cholangiography and risk of common bile duct injury during cholecystectomy. JAMA 289(13):1639-1644

54. Hobbs MS, Mai Q, Knuiman MW, Fletcher DR, Ridout SC (2006) Surgeon experience and trends in intraoperative complications in laparoscopic cholecystectomy. Br J Surg 93(7): 844-853

55. Waage A, Nilsson M (2006) Iatrogenic bile duct injury: a population-based study of 152776 cholecystectomies in the Swedish Inpatient Registry. Arch Surg 141(12):1207-1213

56. Z'graggen K, Wehrli H, Metzger A, Buehler M, Frei E, Klaiber C (1998) Complications of laparoscopic cholecystectomy in Switzerland. A prospective 3-year study of 10,174 patients. Swiss Association of Laparoscopic and Thoracoscopic Surgery. Surg Endosc 12(11):1303-1310

57. Cengiz Y, Jänes A, Grehn A, Israelsson LA (2005) Randomized trial of traditional dissection with electrocautery versus ultrasonic fundus-first dissection in patients undergoing laparoscopic cholecystectomy. Br J Surg 92(7):810-813

58. Catena F, Ansaloni L, Di Saverio S, Gazzotti F, Coccolini F, Pinna AD (2009) Prospective analysis of 101 consecutive cases of laparoscopic cholecystectomy for acute cholecystitis operated with harmonic scalpel. Surg Laparosc Endosc Percutan Tech 19(4):312-316

59. Catena F, Ansaloni L, Di Saverio S, Gazzotti F, Coccolini F, Pinna AD (2009) The HAC Trial (Harmonic for Acute Cholecystitis) Study. Randomized, double-blind, controlled trial of Harmonic $(\mathrm{H})$ versus Monopolar Diathermy $(\mathrm{M})$ for laparoscopic cholecystectomy (LC) for acute cholecystitis (AC) in adults. Tri. Trials 10:34 
60. Hsieh CH (2003) Early laparoscopic cholecystectomy in patients with acute cholecystitis. Am J Surg 185:344-348

61. Pezzilli R, Zerbi A, Di Carlo V, Bassi C, Delle Fave GF (2010) Working Group of the Italian Association for the Study of the Pancreas on Acute Pancreatitis. Practical guidelines for acute pancreatitis. Pancreatology 10:523-535

62. Lowenfels AB, Maisonneuve P, Sullivan T (2009) The changing character of acute pancreatitis: epidemiology, etiology, and prognosis. Curr Gastroenterol Rep 11:97-103

63. Frey CF, Zhou H, Harvey DJ, White RH (2006) The incidence and case-fatality rates of acute biliary, alcoholic, and idiopathic pancreatitis in California, 1994-2001. Pancreas 33:336-344

64. Hirota M, Takada T, Kawarada Y, Hirata K, Mayumi T, Yoshida M, Sekimoto M, Kimura Y, Takeda K, Isaji S, Koizumi M, Otsuki M, Matsuno S (2006) JPN Guidelines for the management of acute pancreatitis: severity assessment of acute pancreatitis. J Hepatobiliary Pancreat Surg 13:33-41

65. Working Party of the British Society of Gastroenterology; Association of Surgeons of Great Britain and Ireland; Pancreatic Society of Great Britain and Ireland; Association of Upper GI Surgeons of Great Britain and Ireland (2005) UK guidelines for the management of acute pancreatitis. Gut 54(suppl 3):1-9

66. Balthazar EJ, Freeny PC, van Sonnenberg E (1994) Imaging and intervention in acute pancreatitis. Radiology 193:297-306

67. Aboulian A, Chan T, Yaghoubian A, Kaji AH, Putnam B, Neville A, Stabile BE, de Virgilio C (2010) Early cholecystectomy safely decreases hospital stay in patients with mild gallstone pancreatitis: a randomized prospective study. Ann Surg 251:615-619

68. Uhl W, Warshaw A, Imrie C, Bassi C, McKay CJ, Lankisch PG, Carter R, Di Magno E, Banks PA, Whitcomb DC, Dervenis C, Ulrich CD, Satake K, Ghaneh P, Hartwig W, Werner J, McEntee G, Neoptolemos JP, Büchler MW, International Association of Pancreatology (2002) IAP Guidelines for the Surgical Management of Acute Pancreatitis. Pancreatology 2:565-573

69. Kimura Y, Takada T, Kawarada Y et al (2006) JPN Guidelines for the management of acute pancreatitis: treatment of gallstone induced acute pancreatitis. J Hepatobiliary Pancreat Surg 13:56-60

70. Nebiker CA, Frey DM, Hamel CT, Oertli D, Kettelhack C (2009) Early versus delayed cholecystectomy in patients with biliary acute pancreatitis. Surgery 145:260-264

71. Sinha R (2008) Early laparoscopic cholecystectomy in acute biliary pancreatitis: the optimal choice? HPB (Oxford) 10: 332-335

72. Taylor E, Wong C (2004) The optimal timing of laparoscopic cholecystectomy in mild gallstone pancreatitis. Am Surg 70:971-997

73. Cameron DR, Goodman AJ (2004) Delayed cholecystectomy for gallstone pancreatitis: re-admissions and outcomes. Ann R Coll Surg Engl 86:358-362

74. Williams EJ, Green J, Beckingham I, Parks R, Martin D, Lombard M (2008) British Society of Gastroenterology, Guidelines on the management of common bile duct stones (CBDS). Gut 57:1004-1021

75. Fernández-Esparrach G, Ginès A, Sánchez M, Pagés M, Pellisé M, Fernández-Cruz L, López-Boado MA, Quintó L, Navarro S, Sendino O, Cárdenas A, Ayuso C, Bordas JM, Llach J, Castells A (2007) Comparison of endoscopic ultrasonography and magnetic resonance cholangiopancreatography in the diagnosis of pancreatobiliary diseases: a prospective study. Am J Gastroenterol 102:1632-1639

76. Petrov MS, Savides TJ (2009) Systematic review of endoscopic ultrasonography versus endoscopic retrograde cholangiopancreatography for suspected choledocholithiasis. $\mathrm{Br}$ J Surg 96:967-974
77. Ayub K, Imada R, Slavin J (2004) Endoscopic retrograde cholangiopancreatography in gallstone-associated acute pancreatitis. Cochrane Database Syst Rev (4):CD003630

78. Rogers SJ, Cello JP, Horn JK, Siperstein AE, Schecter WP, Campbell AR, Mackersie RC, Rodas A, Kreuwel HT, Harris HW (2010) Prospective randomized trial of LC + LCBDE vs $\mathrm{ERCP} / \mathrm{S}+\mathrm{LC}$ for common bile duct stone disease. Arch Surg 145:28-33

79. Morino M, Baracchi F, Miglietta C, Furlan N, Ragona R, Garbarini A (2006) Preoperative endoscopic sphincterotomy versus laparoendoscopic rendezvous in patients with gallbladder and bile duct stones. Ann Surg 244:889-893

80. Clayton ES, Connor S, Alexakis N, Leandros E (2006) Metaanalysis of endoscopy and surgery versus surgery alone for common bile duct stones with the gallbladder in situ. Br J Surg 93:1185-1191

81. Martin DJ, Vernon DR, Toouli J (2006) Surgical versus endoscopic treatment of bile duct stones. Cochrane Database Syst Rev (2):CD003327

82. Mier J, Leon EL, Castillo A, Robledo F, Blanco R (1997) Early versus late necrosectomy in severe necrotizing pancreatitis. Am J Surg 173:71-75

83. Adamson GD, Cuschieri A (2003) Multimedia article. Laparoscopic infracolic necrosectomy for infected pancreatic necrosis. Surg Endosc 17:1675

84. Horvath KD, Kao LS, Wherry KL, Pellegrini CA, Sinanan MN (2001) A technique for laparoscopic-assisted percutaneous drainage of infected pancreatic necrosis and pancreatic abscess. Surg Endosc 15:1221-1225

85. Besselink MG, van Santvoort HC, Schaapherder AF, van Ramshorst B, van Goor H, Gooszen HG, Dutch Acute Pancreatitis Study Group (2007) Feasibility of minimally invasive approaches in patients with infected necrotizing pancreatitis. $\mathrm{Br}$ J Surg 94:604-608

86. Gardner TB, Coelho-Prabhu N, Gordon SR, Gelrud A, Maple JT, Papachristou GI, Freeman ML, Topazian MD, Attam R, Mackenzie TA, Baron TH (2011) Direct endoscopic necrosectomy for the treatment of walled-off pancreatic necrosis: results from a multicenter U.S. series. Gastrointest Endosc 73(4): 718-726

87. Horvath K, Freeny P, Escallon J, Heagerty P, Comstock B, Glickerman DJ, Bulger E, Sinanan M, Langdale L, Kolokythas O, Andrews RT (2010) Safety and efficacy of video-assisted retroperitoneal debridement for infected pancreatic collections: a multicenter, prospective, single-arm phase 2 study. Arch Surg 145:817-825

88. Van Santvoort HC, Besselink MG, Bakker OJ, Hofker HS, Boermeester MA, Dejong CH, van Goor H, Schaapherder AF, van Eijck CH, Bollen TL, van Ramshorst B, Nieuwenhuijs VB, Timmer R, Laméris JS, Kruyt PM, Manusama ER, van der Harst E, van der Schelling GP, Karsten T, Hesselink EJ, van Laarhoven CJ, Rosman C, Bosscha K, de Wit RJ, Houdijk AP, van Leeuwen MS, Buskens E, Gooszen HG, Dutch Pancreatitis Study Group (2010) A step-up approach or open necrosectomy for necrotizing pancreatitis. N Engl J Med 362:1491-1502

89. Mentula P, Hienonen P, Kemppainen E, Puolakkainen P, Leppäniemi A (2010) Surgical decompression for abdominal compartment syndrome in severe acute pancreatitis. Arch Surg 145:764-769

90. De Waele JJ, Leppäniemi AK (2009) Intra-abdominal hypertension in acute pancreatitis. World J Surg 33:1128-1133

91. Chen H, Li F, Sun JB, Jia JG (2008) Abdominal compartment syndrome in patients with severe acute pancreatitis in early stage. World J Gastroenterol 14:3541-3548

92. Semm K (1983) Die endoskopische appendektomie. Gynakol Prax 7:131 
93. Korndorffer JR Jr, Fellinger E, Reed W (2010) SAGES guideline for laparoscopic appendectomy. Surg Endosc 24(4):757761

94. Vettoretto N, Gobbi S, Corradi A, Belli F, Piccolo D, Pernazza G, Mannino L (2011) Italian Association of Hospital Surgeons (Associazione dei Chirurghi Ospedalieri Italiani). Consensus conference on laparoscopic appendectomy: development of guidelines. Colorectal Dis 13(7):748-754

95. Toorenvliet BR, Wiersma F, Bakker RF, Merkus JW, Breslau PJ, Hamming JF (2010) Routine ultrasound and limited computed tomography for the diagnosis of acute appendicitis. World J Surg 34:2278-2285

96. Al-Khayal KA, Al-Omran MA (2007) Computed tomography and ultrasonography in the diagnosis of equivocal acute appendicitis. A meta-analysis. Saudi Med J 28(2):173-180

97. Varadhan KK, Humes DJ, Neal KR, Lobo DN (2010) Antibiotic therapy versus appendectomy for acute appendicitis: a metaanalysis. World J Surg 34(2):199-209

98. Sauerland S, Jaschinski T, Neugebauer EA (2010) Laparoscopic versus open surgery for suspected appendicitis. Cochrane Database Syst Rev (10):CD001546

99. Kirshtein B, Perry ZH, Mizrahi S, Lantsberg L (2009) Value of laparoscopic appendectomy in the elderly patient. World J Surg 33:918-922

100. Corneille MG, Steigelman MB, Myers JG, Jundt J, Dent DL, Lopez PP, Cohn SM, Stewart RM (2007) Laparoscopic appendectomy is superior to open appendectomy in obese patients. Am J Surg 194(6):877-880

101. Tzovaras G, Baloyiannis I, Kouritas V, Symeonidis D, Spyridakis M, Poultsidi A, Tepetes K, Zacharoulis D (2010) Laparoscopic versus open appendectomy in men: a prospective randomized trial. Surg Endosc 24(12):2987-2992

102. Markides G, Subar D, Riyad K (2010) Laparoscopic versus open appendectomy in adults with complicated appendicitis: a systematic review and meta-analysis. World J Surg 34:2026-2040

103. Dindo D, Demartines N, Clavien PA (2004) Classification of surgical complications. A new proposal with evaluation in a cohort of 6336 patients and results of a survey. Ann Surg 240(2):205-213

104. Ohno Y, Furui J, Kanematsu T (2004) Treatment strategy when using intraoperative peritoneal lavage for perforated appendicitis in children: a preliminary report. Pediatr Surg Int 20:534-537

105. Kapischke M, Caliebe A, Tepel J, Schulz T, Hedderich J (2006) Open versus laparoscopic appendectomy: a critical review. Surg Endosc 20:1060-1068

106. Jackson H, Granger S, Price R, Rollins M, Earle D, Richardson W, Fanelli R (2008) Diagnosis and laparoscopic treatment of surgical diseases during pregnancy: an evidence-based review. Surg Endosc 22(9): 1917-1927

107. Walsh CA, Tang T, Walsh SR (2008) Laparoscopic vs open appendectomy in pregnancy: a systematic review. Int J Surg 6:339-344

108. Grimes C, Chin D, Bailey C, Gergely S, Harris A (2010) Appendiceal faecaliths are associated with right iliac fossa pain. Ann R Coll Surg Engl 92(1):61-64

109. Navez B, Therasse A (2003) Should every patient undergoing laparoscopy for clinical diagnosis of appendicitis have an appendicectomy? Acta Chir Belg 103(1):87-89

110. Kazemeier G, in't Hof KH, Saad S, Bonjer HJ, Sauerland S (2006) Securing the appendiceal stump in laparoscopic appendectomy: evidence for routine stapling? Surg Endosc 20: 1473-1476

111. Sauerland S, Kazemier G (2007) Appendix stump closure during laparoscopic appendectomy (Protocol). Cochrane Database Syst Rev (2):CD006437
112. Sajid MS, Khan MA, Cheek E, Baig MK (2009) Needlescopic versus laparoscopic appendectomy: a systematic review. Can J Surg 52:129-134

113. Langer K (1861) "Zur Anatomie und Physiologie der Haut. Über die Spaltbarkeit der Cutis." Sitzungsbericht der Mathematisch-naturwissenschaftlichen Classe der Wiener Kaiserlichen Academie der Wissenschaften Abt. 44

114. Teoh AY, Chiu PW, Wong TC, Wong SK, Lai PB, Ng EK (2011) A case-controlled comparison of single-access versus conventional three-port laparoscopic appendectomy. Surg Endosc 25(5): 1415-1419

115. Park PO, Bergstrom M (2010) Transgastric peritoneoscopy and appendectomy: thoughts on our first experience in humans. Endoscopy 42:81-84

116. Kuzma J (2008) Randomized clinical trial to compare the length of hospital stay and morbidity for early feeding with opioidsparing analgesia versus traditional care after open appendectomy. Clin Nutr 27(5):694-699

117. Gorenoi V, Dintsios CM, Schonermark M, Hagen A (2006) Laparoskopische vs. offene Appendektomie. Systematische Ubersicht zur medizinischen Wirksamkeit und gesundheitsoko nomische Analyse. HTA-Bericht 148. In: Deutsche Agentur fur Health Technology Assessment des Deutschen Instituts fur Medizinische Dokumentation und Information (DAHTA@DIMDI) (Hrsg.). Schriftenreihe Health Technology Assessment (HTA) in der Bundesrepublik Deutschland. Koln: DAHTA-Datenbank des DIMDI

118. Chu T, Chandhoke RA, Smith PC, Schwaitzberg SD (2011) The impact of surgeon choice on the cost of performing laparoscopic appendectomy. Surg Endosc 25(4):1187-1191

119. Wong K, Duncan T, Pearson A (2007) Unsupervised laparoscopic appendectomy by surgical trainees is safe and timeeffective. Asian J Surg 30(3):161-166

120. McWilliams GD, Hill MJ, Dietrich CS 3rd (2008) Gynecologic emergencies. Surg Clin North Am 88:265-283

121. Chung RS, Diaz JJ, Chari V (1998) Efficacy of routine laparoscopy for the acute abdomen. Surg Endosc 12:219-222

122. Agresta F, Mazzarolo G, Ciardo LF, Bedin N (2008) The laparoscopic approach in abdominal emergencies: has the attitude changed? A single-center review of a 15-year experience. Surg Endosc 22:1255-1262

123. Porpora MG, Gomel V (1997) The role of laparoscopy in the management of pelvic pain in women of reproductive age. Fertil Steril 68:765-779

124. Golash V, Willson PD (2005) Early laparoscopy as a routine procedure in the management of acute abdominal pain: a review of 1,320 patients. Surg Endosc 19:882-885

125. Al-Mulhim AS, Nasser MA, Abdullah MM, Ali AM, Kaman L (2008) Emergency laparoscopy for acute abdominal conditions: a prospective study. J Laparoendosc Adv Surg Tech A 18: 599-602

126. Karamanakos SN, Sdralis E, Panagiotopoulos S, Kehagias I (2010) Laparoscopy in the emergency setting: a retrospective review of 540 patients with acute abdominal pain. Surg Laparosc Endosc Percutan Tech 20:119-124

127. Kontoravdis A, Chryssikopoulos A, Hassiakos D, Liapis A, Zourlas PA (1996) The diagnostic value of laparoscopy in 2365 patients with acute and chronic pelvic pain. Int J Gynaecol Obstet 52:243-248

128. Magos AL, Baumannn R, Turnbull AC (1989) Managing gynaecological emergencies with laparoscopy. Br Med J 299: 371-374

129. Navarrete Aulestia S, Cantele H, Leyba JL, Navarrete M, Navarrete Llopla S (2003) Laparoscopic diagnosis and treatment in gynecologic emergencies. J Soc Laparoendosc Surg 7:239-242 
130. Easter DW, Cuschieri A, Nathanson LK, Lavelle-Jones M (1992) The utility of diagnostic laparoscopy for abdominal disorders. Audit of 120 patients. Arch Surg 127:379-383

131. Ou CS, Rowbotham R (2000) Laparoscopic diagnosis and treatment of nontraumatic acute abdominal pain in women. J Laparoendosc Adv Surg Tech A 10:41-45

132. Promecene PA (2002) Laparoscopy in gynecologic emergencies. Semin Laparosc Surg 9:64-75

133. Valentin L (2009) Characterising acute gynaecological pathology with ultrasound: an overview and case examples. Best Pract Res Clin Obstet Gynaecol 23:577-593

134. Vandermeer FQ, Wong-You-Cheong JJ (2009) Imaging of acute pelvic pain. Clin Obstet Gynecol 52:2-20

135. Andreotti RF, Lee SI, Choy G, DeJesus Allison SO, Bennett GL, Brown DL, Glanc P, Horrow MM, Javitt MC, Lev-Toaff AS, Podrasky AE, Scoutt LM, Zelop C (2009) ACR Appropriateness Criteria on acute pelvic pain in the reproductive age group. J Am Coll Radiol 6:235-241

136. Potter AW, Chandrasekhar CA (2008) US and CT evaluation of acute pelvic pain of gynecologic origin in nonpregnant premenopausal patients. Radiographics 28:1645-1659

137. Heverhagen JT, Klose KJ (2009) MR imaging for acute lower abdominal and pelvic pain. Radiographics 29:1781-1796

138. Mikkelsen AL, Felding C (1990) Laparoscopy and ultrasound examination in women with acute pelvic pain. Gynecol Obstet Invest 30:162-164

139. Allen LA, Schoon MG (1983) Laparoscopic diagnosis of acute pelvic inflammatory disease. Br J Obstet Gynaecol 90:966-968

140. Taylor EW, Kennedy CA, Dunham RH, Bloch JH (1995) Diagnostic laparoscopy in women with acute abdominal pain. Surg Laparosc Endosc 5:125-128

141. Ates M, Sevil S, Bulbul M (2008) Routine use of laparoscopy in patients with clinically doubtful diagnosis of appendicitis. J Laparoendosc Adv Surg Tech A 18:189-193

142. Varma R, Gupta J (2009) Tubal ectopic pregnancy. Clin Evid (Online) 2009. pii:1406

143. Horne AW, Duncan WC, Critchley HO (2010) The need for serum biomarker development for diagnosing and excluding tubal ectopic pregnancy. Acta Obstet Gynecol Scand 89:299-301

144. Hajenius PJ, Mol F, Mol BW, Bossuyt PM, Ankum WM, Van der Veen F (2007) Interventions for tubal ectopic pregnancy. Cochrane Database Syst Rev (1):CD000324

145. Mol F, Mol BW, Ankum WM, van der Veen F, Hajenius PJ (2008) Current evidence on surgery, systemic methotrexate and expectant management in the treatment of tubal ectopic pregnancy: a systematic review and meta-analysis. Hum Reprod Update 14:309-319

146. Bignardi T, Condous G (2009) Current evidence about treatments for ectopic pregnancy: need for a rethink on RCTs. Hum Reprod Update 15:261-262

147. Gray DT, Thorburn J, Lundorff P, Strandell A, Lindblom B (1995) A cost-effectiveness study of a randomised trial of laparoscopy versus laparotomy for ectopic pregnancy. Lancet 345:1139-1143

148. Lundorff P, Thorburn J, Hahlin M, Kallfelt B, Lindblom B (1991) Laparoscopic surgery in ectopic pregnancy. A randomized trial versus laparotomy. Acta Obstet Gynecol Scand 70:343-348

149. Lundorff P, Thorburn J, Lindblom B (1992) Fertility outcome after conservative surgical treatment of ectopic pregnancy evaluated in a randomized trial. Fertil Steril 57:998-1002

150. Vermesh M, Silva PD, Rosen GF, Stein AL, Fossum GT, Sauer MV (1989) Management of unruptured ectopic gestation by linear salpingostomy: a prospective, randomized clinical trial of laparoscopy versus laparotomy. Obstet Gynecol 73:400-404
151. Fernandez H, Marchal L, Vincent Y (1998) Fertility after radical surgery for tubal pregnancy. Fertil Steril 70:680-686

152. Murphy AA, Nager CW, Wujek JJ, Kettel LM, Torp VA, Chin HG (1992) Operative laparoscopy versus laparotomy for the management of ectopic pregnancy: a prospective trial. Fertil Steril 57:1180-1185

153. Oelsner G, Shashar D (2006) Adnexal torsion. Clin Obstet Gynecol 49:459-463

154. Lo LM, Chang SD, Horng SG, Yang TY, Lee CL, Liang CC (2008) Laparoscopy versus laparotomy for surgical intervention of ovarian torsion. J Obstet Gynaecol Res 34:1020-1025

155. Balci O, Icen MS, Mahmoud AS, Capar M, Colakoglu MC (2011) Management and outcomes of adnexal torsion: a 5-year experience. Arch Gynecol Obstet 284(3):643-646

156. Cohen SB, Wattiez A, Seidman DS, Goldenberg M, Admon D, Mashiach S, Oelsner G (2003) Laparoscopy versus laparotomy for detorsion and sparing of twisted ischemic adnexa. JSLS 7:295-299

157. Medeiros LR, Rosa DD, Bozzetti MC, Fachel JM, Furness S, Garry R, Rosa MI, Stein AT (2009) Laparoscopy versus laparotomy for benign ovarian tumour. Cochrane Database Syst Rev (2):CD004751

158. Mais V, Ajossa S, Piras B, Marongiu D, Guerriero S, Melis GB (1995) Treatment of nonendometriotic benign adnexal cysts; a randomized comparison of laparoscopy and laparotomy. Obstet Gynecol 86:770-774

159. Yuen PM, Yu KM, Yip SK, Lau WC, Rogers MS, Chang A (1997) A randomized prospective study of laparoscopy and laparotomy in the management of benign ovarian masses. Am J Obstet Gynecol 177:109-114

160. Nitke S, Goldman GA, Fisch B, Kaplan B, Ovadia J (1996) The management of dermoid cysts - a comparative study of laparoscopy and laparotomy. Isr J Med Sci 32:1177-1179

161. Ferrero S, Remorgida V, Venturini PL (2010) Endometriosis. Clin Evid (Online)

162. Almeida Filho DP, Oliveira LJ, Amaral VF (2008) Accuracy of laparoscopy for assessing patients with endometriosis. Sao Paulo Med J 126:305-308

163. Giudice LC (2010) Clinical practice. Endometriosis. N Engl J Med 362:2389-2398

164. Jacobson TZ, Barlow DH, Garry R, Koninckx P (2001) Laparoscopic surgery for pelvic pain associated with endometriosis. Cochrane Database Syst Rev (4):CD001300

165. Abbott J, Hawe J, Hunter D, Holmes M, Finn P, Garry R (2004) Laparoscopic excision of endometriosis; a randomized, placebo controlled trial. Fertil Steril 82:878-884

166. Sutton CJG, Pooley AS, Ewen SP, Haines P (1997) Follow-up report on a randomized controlled trial of laser laparoscopy in the treatment of pelvic pain associated with minimal to moderate endometriosis. Fertil Steril 68:1070-1074

167. Morino M, Pellegrino L, Castagna E, Farinella E, Mao P (2006) Acute nonspecific abdominal pain: a randomized, controlled trial comparing early laparoscopy versus clinical observation. Ann Surg 244:881-886

168. Bevan CD, Johal BJ, Mumtaz G, Ridgway GL, Siddle NC (1995) Clinical, laparoscopic and microbiological findings in acute salpingitis; report on a United Kingdom cohort. Br J Obstet Gynaecol 102:407-414

169. Morcos R, Frost N, Hnat M, Petrunak A, Caldito G (1993) Laparoscopic versus clinical diagnosis of acute pelvic inflammatory disease. J Reprod Med 38:53-56

170. Soper DE (2010) Pelvic inflammatory disease. Obstet Gynecol 116:419-428

171. Granberg S, Gjelland K, Ekerhovd E (2009) The management of pelvic abscess. Best Pract Res Clin Obstet Gynaecol 23:667-678 
172. Perez-Medina T, Huertas MA, Bajo JM (1996) Early ultrasoundguided transvaginal drainage of tubo-ovarian abscesses: a randomized study. Ultrasound Obstet Gynecol 7:435-438

173. Soper DE (1991) Diagnosis and laparoscopic grading of acute salpingitis. Am J Obstet Gynecol 164:1370-1376

174. Teisala K, Heinonen PK, Punnonen R (1990) Laparoscopic diagnosis and treatment of acute pyosalpinx. J Reprod Med 35(1):19-21

175. Teng SW, Tseng JY, Chang CK, Li CT, Chen YJ, Wang PH (2003) Comparison of laparoscopy and laparotomy in managing hemodynamically stable patients with ruptured corpus luteum with hemoperitoneum. J Am Assoc Gynecol Laparosc 10: 474-477

176. Society of American Gastrointestinal and Endoscopic Surgeons (SAGES) (2007) Guidelines for diagnostic laparoscopy practice/ clinical guidelines. SAGES, Los Angeles

177. American College of Emergency Physicians (2000) Clinical policy: critical issues for the initial evaluation and management of patients presenting with a chief complaint of nontraumatic acute abdominal pain. Am Emerg Med 36:406-415

178. Gerhardt RT, Nelson BK, Keenan S, Kernan L, MacKersie A, Lane MS (2005) Derivation of a clinical guideline for the assessment of nonspecific abdominal pain: the Guideline for Abdominal Pain in the ED Setting (GAPEDS) Phase 1 Study. Am J Emerg Med 23:709-717

179. Ng CS, Watson CJ, Palmer CR, See TC, Beharry NA, Housden BA, Bradley JA, Dixon AK (2002) Evaluation of early abdomino-pelvic computed tomography in patients with acute abdominal pain of unknown cause: a prospective randomized study. BMJ 325:1-4

180. Sala E, Beadsmoore C, Gibbons D, Shaw A, Gaskarth M, GrootWassink T, Watson C, Dixon AK (2009) Unexpected changes in clinical diagnosis: early abdomino-pelvic CT compared with clinical evaluation. Abdom Imaging 34:783-787

181. Sözüer EM, Bedirli A, Ulusal M, Kayhan E, Yilmaz Z (2000) Laparoscopy for diagnosis and treatment of acute abdominal pain. J Laparoendosc Adv Surg Tech A 10:203-207

182. Poulin EC, Schlachta CM, Mamazza J (2000) Early laparoscopy to help diagnose acute nonspecific abdominal pain. Lancet 355:861-863

183. Stefanidis D, Richardson WS, Chang L, Earle DB, Fanelli RD (2009) The role of diagnostic laparoscopy for acute abdominal conditions: an evidence based review. Surg Endosc 23:16-23

184. Gagné DJ, Malay MB, Hogle NJ, Fowler DL (2002) Bedside diagnostic minilaparoscopy in the intensive care patient. Surgery 131(5):491-496

185. Pecoraro AP, Cacchione RN, Sayad P, Williams ME, Ferzli GS (2001) The routine use of diagnostic laparoscopy in the intensive care unit. Surg Endosc 15(7):638-641

186. Champault G, Rizk N, Lauroy J, Olivares P, Belhassen A, Boutelier P (1993) Right iliac fossa in women: conventional diagnostic approach versus primary laparoscopy. A controlled study (65 cases)]. Ann Chir 47:316-319

187. Decadt B, Sussman L, Lewis MP, Secker A, Cohen L, Rogers C, Patel A, Rhodes M (1999) Randomized clinical trial of early laparoscopy in the management of acute non-specific abdominal pain. Br J Surg 86:1383-1386

188. Maggio AQ, Reece-Smith AM, Tang TY, Sadat U, Walsh SR (2008) Early laparoscopy versus active observation in acute abdominal pain: systematic review and meta-analysis. Int J Surg 6:400-403

189. Hainaux B, Agneessen E, Bertinotti R, De Maertelaer V, Rubesova E, Capelluto E, Moschopoulos C (2006) Accuracy of MDCT in predicting site of gastrointestinal tract perforation. AJR Am J Roentgenol 187:1179-1183
190. Earls JP, Dachman AH, Colon E, Garrett MG, Molloy M (1993) Prevalence and duration of postoperative pneumoperitoneum: sensitivity of CT vs left lateral decubitus radiography. AJR Am J Roentgenol 161:781-785

191. Chen CH, Huang HS, Yang CC, Yeh YH (2001) The features of perforated peptic ulcers in conventional computed tomography. Hepatogastroenterology 48:1393-1396

192. Lunevicius R, Morkevicius M (2005) Systemic review comparing laparoscopic and open repair for perforated peptic ulcer. Br J Surg 92:1195-1207

193. Siu WT, Leong HT, Law BKB, Chau CH, Li AC, Fung KH, Tai YP, Li MKW (2002) Laparoscopic repair for perforated peptic ulcer: a randomized controlled trial. Ann Surg 235(3):313-319

194. Lau H (2004) Laparoscopic repair of perforated peptic ulcer: a meta-analysis. Surg Endosc 18:1013-1021

195. Boey J, Wong J, Ong GB (1982) A prospective study of operative risk factors in perforated duodenal ulcers. Ann Surg 195(3):265-269

196. Agresta F, Michelet I, Coluci G, Bedin N (2000) Emergency laparoscopy: a community hospital experience. Surg. Endosc 14:484-487

197. Notash AY, Salimi J, Rahimian H, Fersharaki MH, Abbassi A (2005) Evaluation of Mannheim Peritonitis Index and multiple failure score in patients with peritonitis. Ind J Gastroenterol 24:197-200

198. Lee FY, Leung KL, Lai BS, Ng SS, Dexter S, Lau WY (2001) Predicting mortality and morbidity of patients operated on for perforated peptic ulcers. Arch Surg 136:90-94

199. Lau WY, Leung KL, Kwong KH, Davey C, Robertson C, Dawson JJ, Chung SC, Li AK (1996) A randomized study comparing laparoscopic versus open repair of perforated peptic ulcer using suture or sutureless technique. Ann Surg 224(2): 131-138

200. Sanabria AE, Morales CH, Villegas MI (2005) Laparoscopic repair for perforated peptic ulcer disease. Cochrane Database Syst Rev (4):CD004778

201. Lagoo S, Mc Mahon RL, Kalkharu M, Pappas TN, Eubanks S (2002) The sixth decision regarding perforated duodenal ulcer. JSLS 6:359-368

202. Katkhouda N, Mavor E, Mason RJ, Campos GMR, Soroushyari A, Berne TV (1999) Laparoscopic repair of perforated duodenal ulcers: outcome and efficacy in 30 consecutive patients. Arch Surg 134:845-850

203. Robertson GS, Wemyss-Holden SA, Maddern GJ (2000) Laparoscopic repair of perforated duodenal ulcers. The role of laparoscopy in generalized peritonitis. Ann R Coll Surg Engl 82:6-10

204. Miserez M, Eypasch E, Spangenberger W, Lefering R, Troidl H (1996) Laparoscopic and conventional closure of perforated peptic ulcer: a comparison. Surg Endosc 10:831-836

205. Bertleff M, Halm JA, Bemelman WA, van der Ham AC, van der Harst E, Oei HI, Smulders JF, Steyerberg EW, Lange JF (2009) Randomized clinical trial of laparoscopic versus open repair of the perforated peptic ulcer: the LAMA trial. World J Surg 33:1368-1373

206. Alvarez JA, Baldonedo RF, Bear IG, Otero J, Pire G, Alvarez P, Jorge JI (2007) Presentation, management and outcome of acute sigmoid diverticulitis requiring hospitalization. Dig Surg 24:471-476

207. Shaikh S, Krukowski ZH (2007) Outcome of a conservative policy for managing acute sigmoid diverticulitis. Br J Surg 94:876-879

208. Guller U, Jain N, Hervey S, Purves H, Pietrobon R (2003) Laparoscopic vs open colectomy: outcomes comparison based on large nationwide databases. Arch Surg 138:1179-1186 
209. Hinojosa MW, Murrell ZA, Konyalian VR, Mills S, Nguyen NT, Stamos MJ (2007) Comparison of laparoscopic vs open sigmoid colectomy for benign and malignant disease at academic medical centers. J Gastrointest Surg 11:1423-1429

210. Klarenbeek BR, Veenhof AA, Bergamaschi R, van der Peet DL, van den Broek WT, de Lange ES, Bemelman WA, Heres P, Lacy AM, Engel AF, Cuesta MA (2009) Laparoscopic sigmoid resection for diverticulitis decreases major morbidity rates: a randomized control trial: short-term results of the Sigma Trial. Ann Surg 249:39-44

211. Faynsod M, Stamos MJ, Arnell T, Borden C, Udani S, Vargas H (2000) A case-control study of laparoscopic versus open sigmoid colectomy for diverticulitis. Am Surg 66:841-843

212. Dwivedi A, Chahin F, Agrawal S, Chau WY, Tootla A, Tootla F, Silva YJ (2002) Laparoscopic colectomy vs. open colectomy for sigmoid diverticular disease. Dis Colon Rectum 45: $1309-1314$

213. Lawrence DM, Pasquale MD, Wasser TE (2003) Laparoscopic versus open sigmoid colectomy for diverticulitis. Am Surg 69:499-503

214. Gonzalez R, Smith CD, Mattar SG, Venkatesh KR, Mason E, Duncan T, Wilson R, Miller J, Ramshaw BJ (2004) Laparoscopic vs open resection for the treatment of diverticular disease. Surg Endosc 18:276-280

215. Alves A, Panis Y, Slim K, Heyd B, Kwiatkowski F, Mantion G (2005) French multicentre prospective observational study of laparoscopic versus open colectomy for sigmoid diverticular disease. Br J Surg 92:1520-1525

216. Senagore AJ, Duepree HJ, Delaney CP, Dissanaike S, Brady KM, Fazio VW (2002) Cost structure of laparoscopic and open sigmoid colectomy for diverticular disease: similarities and differences. Dis Colon Rectum 45:485-490

217. Hinchey EJ, Schaal PG, Richards GK (1978) Treatment of perforated diverticular disease of the colon. Adv Surg 12: $85-109$

218. Sher ME, Agachan F, Bortul M, Nogueras JJ, Weiss EG, Wexner SD (1997) Laparoscopic surgery for diverticulitis. Surg Endosc 11:264-267

219. Kohler L, Sauerland S, Neugebauer E (1999) Diagnosis and treatment of diverticular disease: results of a consensus development conference. The Scientific Committee of the European Association for Endoscopic Surgery. Surg Endosc 13:430-436

220. Durmishi Y, Gervaz P, Brandt D, Bucher P, Platon A, Morel P, Poletti PA (2006) Results from percutaneous drainage of Hinchey stage II diverticulitis guided by computed tomography scan. Surg Endosc 20:1129-1133

221. Brandt D, Gervaz P, Durmishi Y, Platon A, Morel P, Poletti PA (2006) Percutaneous CT scan-guided drainage vs. antibiotherapy alone for Hinchey II diverticulitis: a case-control study. Dis Colon Rectum 49:1533-1538

222. Kumar RR, Kim JT, Haukoos JS, Macias LH, Dixon MR, Stamos MJ, Konyalian VR (2006) Factors affecting the successful management of intra-abdominal abscesses with antibiotics and the need for percutaneous drainage. Dis Colon Rectum 49:183-189

223. O'Sullivan GC, Murphy D, O'Brien MG, Ireland A (1996) Laparoscopic management of generalized peritonitis due to perforated colonic diverticula. Am J Surg 171:432-434

224. Faranda C, Barrat C, Catheline JM, Champault GG (2000) Two stage laparoscopic management of generalized peritonitis due to perforated sigmoid diverticula: eighteen cases. Surg Laparosc Endosc Percutan Tech 10:135-138

225. Taylor CJ, Layani L, Ghusn MA, White SI (2006) Perforated diverticulitis managed by laparoscopic lavage. ANZ J Surg 76:962-965
226. Bretagnol F, Pautrat K, Mor C, Benchellal Z, Huten N, de Calan L (2008) Emergency laparoscopic management of perforated sigmoid diverticulitis: a promising alternative to more radical procedures. J Am Coll Surg 206:654-657

227. Franklin ME Jr, Portillo G, Trevino JM, Gonzalez JJ, Glass JL (2008) Long-term experience with the laparoscopic approach to perforated diverticulitis plus generalized peritonitis. World $\mathrm{J}$ Surg 32:1507-1511

228. Karoui M, Champault A, Pautrat K, Valleur P, Cherqui D, Champault G (2009) Laparoscopic peritoneal lavage or primary anastomosis with defunctioning stoma for Hinchey 3 complicated diverticulitis: results of a comparative study. Dis Colon Rectum 52:609-615

229. Alamili M, Gögenur I, Rosenberg J (2009) Acute complicated diverticulitis managed by laparoscopic lavage. Dis Colon Rectum 52:1345-1349

230. Favuzza J, Friel JC, Kelly JJ, Perugini R, Counihan TC (2009) Benefits of laparoscopic peritoneal lavage for complicated sigmoid diverticulitis. Int J Colorectal Dis 24:797-801

231. Stocchi L (2010) Current indications and role of surgery in the management of sigmoid diverticulitis. World J Gastroenterol $16: 804-817$

232. Myers E, Hurley M, O'Sullivan GC, Kavanagh D, Wilson I, Winter DC (2008) Laparoscopic peritoneal lavage for generalized peritonitis due to perforated diverticulitis. Br J Surg 95:97-101

233. Agaba EA, Zaidi RM, Ramzy P, Aftab M, Rubach E, Gecelter G, Ravikumar TS, Denoto G (2009) Laparoscopic Hartmann's procedure: a viable option for treatment of acutely perforated diverticulitis. Surg Endosc 23:1483-1486

234. Titu L, Zafar N, Phillips S, Greenslade G, Dixon A (2009) Emergency laparoscopic surgery for complicated diverticular disease. Colorectal Dis 11:401-404

235. Chouillard E, Maggiori L, Ata T, Jarbaoui S, Rivkine E, Benhaim L, Ghiles E, Etienne JC, Fingerhut A (2007) Laparoscopic twostage left colonic resection for patients with peritonitis caused by acute diverticulitis. Dis Colon Rectum 50:1157-1163

236. Zdichavsky M, Granderath FA, Blumenstock G, Kramer M, Kuper MA, Konigsrainer A (2010) Acute laparoscopic intervention for diverticular disease: a feasible approach. Langenbecks Arch Surg 395:41-48

237. Navez B, Tassetti V, Scohy JJ, Mutter D, Guiot P, Evrard S, Marescaux J (1998) Laparoscopic management of acute peritonitis. Br J Surg 85:32-36

238. Bastug DF (1991) Laparoscopic adhesiolysis for small bowel obstruction. Surg Laparosc Endosc 1:259-262

239. Souba WW, Fink MP, Jurkovich GJ, Kaiser LR, Pearce WH, Pemberton JH, Soper NJ (2006) ACS surgery: principles and practice. WebMD Professional Publishing, New York

240. Miller G, Boman J, Shrier J, Gordon PH (2000) Etiology of small bowel obstruction. Am J Surg 180:33-36

241. Duron JJ, Jourdan-Da Silva N, Tezenas du Montcel S, Berger A, Muscari F, Hennet H, Veyrieres M, Hay JM (2006) Adhesive postoperative small bowel obstruction: incidence and risk factors of recurrence after surgical treatment. A multicenter prospective study. Ann Surg 244:750-757

242. Cirocchi R, Abraha I, Farinella E, Montedori A, Sciannameo F (2010) Laparoscopic versus open surgery in small bowel obstruction (review). The Cochrane Collaboration. Cochrane Database Syst Rev (2):CD007511

243. Majewski W (2006) How should a patient with acute abdomen be managed? Adhesion 9:14-16

244. Iorgulescu R, Iordache M, Ilie R, Dragomirescu C (2005) Laparoscopic surgery for small bowel obstruction. Chirurgia 101:313-318 
245. Khaikin M, Schneidereit N, Cera S, Sands D, Efron J, Weiss G, Nogueras JJ, Vernava AM, Wexner SD (2007) Laparoscopic vs. open surgery for acute adhesive small-bowel obstruction: patients' outcome and cost-effectiveness. Surg Endosc 21: $742-746$

246. Cavaliere D, Schirru A, Caristo I, Bianchi M, Cosce U, Cavaliere P (2005) Laparoscopic management of small-bowel obstruction. Chir Ital 57:215-220

247. Johanet H, Marmuse JP (2005) Occlusion aigue du grele sur bride. Prevention et traitement des occlusions du grele su bride. Referentiel Association Française de Chirurgie (A.F.C.) no. 4513 créé(e) le 28/04/05 par Pr Denis Collet

248. Zerey M, Sechrist CW, Kercher KW, Sing RF, Matthews BD, Heniford BT (2007) Laparoscopic management of adhesive small bowel obstruction. Am Surg 73:773-778

249. Cirocchi R, Giustozzi G, De Sol A et al (2007) Laparoscopic adhesiolysis in acute small bowel obstruction. Minerva Chir 62(6):477-488

250. Binenbaum SJ, Goldfarb MA (2006) Inadvertent enterotomy in minimally invasive abdominal surgery. JSLS 10:336-340

251. Qureshi I, Awad ZT (2010) Predictors of failure of the laparoscopic approach for the management of small bowel obstruction. Am Surg 76(9):947-950

252. Grafen FC, Neuhaus V, Schob O, Turina M (2010) Management of acute small bowel obstruction from intestinal adhesions: indications for laparoscopic surgery in a community teaching hospital. Langenbecks Arch Surg 395(1):57-63

253. Diaz JJ Jr, Bokhari F, Mowery NT, Acosta JA, Block EF, Bromberg WJ, Collier BR, Cullinane DC, Dwyer KM, Griffen MM, Mayberry JC, Jerome R (2008) Guidelines for management of small bowel obstruction. J Trauma 64:1651-1664

254. SAGES (2008) Diagnostic laparoscopy guidelines. Surg Endosc 22:1353-1383

255. Farinella E, Roberto Cirocchi R, La Mura F, Morelli U, Cattorini L, Delmonaco P, Migliaccio C, De Sol AA, Cozzaglio L, Sciannameo F (2009) Feasibility of laparoscopy for small bowel obstruction. World J Emerg Surg 4:3

256. Levard H (2001) Laparoscopic treatment of acute small bowel obstruction: a multicentre retrospective study. ANZ J Surg 71:641-646

257. Suter M, Zermatten P, Halkic N, Martinet O, Bettschart V (2000) Laparoscopic management of mechanical small bowel obstruction: are there predictors of success or failure? Surg Endosc 14:478-483

258. Zago M, Mariani D, Kurihara H, Turconi MG, Poldi D, Rosati R (2010) Selection criteria analysis for laparoscopic treatment of small bowel obstruction on a 100 patients series. Eur J Trauma Emerg Surg 36:120

259. Navez B, Arimont JM, Guit P (1998) Laparoscopic approach in acute small bowel obtruction. A review of 68 patients. Hepatogastroenterology 45:2146-2150

260. Léon EL, Metzger A, Tsiotos GG et al (1998) Laparoscopic management of small bowel obstruction: indication and outcomes. J Gastrointest Surg 2:132-140

261. Kulah B, Kulacoglu IH, Oruc MT, Duzgun AP, Moran M, Ozmen MM, Coskun F (2001) Presentation and outcome of incarcerated external hernias in adults. Am J Surg 181(2): $101-104$

262. Gallegos NC, Dawson J, Jarvis M, Hobsley M (1991) Risk of strangulation in groin hernias. Br J Surg 78(10):1171-1173

263. Bekoe S (1973) Prospective analysis of the management of incarcerated and strangulated inguinal hernias. Am J Surg 126(5):665-668

264. Brasso K, Løndal Nielsen K, Christiansen J (1989) Long-term results of surgery for incarcerated groin hernia. Acta Chir Scand 155(11-12):583-585
265. MacFadyen BV Jr, Mathis CR (1994) Inguinal herniorrhaphy: complications and recurrences. Semin Laparosc Surg 1(2): 128-140

266. Nilsson H, Stylianidis G, Haapamäki M, Nilsson E, Nordin P (2007) Mortality after groin hernia surgery. Ann Surg 245(4): 656-660

267. Watson SD, Saye W, Hollier PA (1993) Combined laparoscopic incarcerated herniorrhaphy and small bowel resection. Surg Laparosc Endosc 3(2):106-108

268. McCormack K, Scott NW, Go PM, Ross S, Grant AM, EU Hernia Trialists Collaboration (2003) Laparoscopic techniques versus open techniques for inguinal hernia repair. Cochrane Database Syst Rev (1):CD001785

269. Dedemadi G, Sgourakis G, Radtke A, Dounavis A, Gockel I, Fouzas I, Karaliotas C, Anagnostou E (2010) Laparoscopic versus open mesh repair for recurrent inguinal hernia: a metaanalysis of outcomes. Am J Surg 200(2):291-297

270. Deeba S, Purkayastha S, Paraskevas P, Athanasiou T, Darzi A, Zacharakis E (2009) Laparoscopic approach to incarcerated and strangulated inguinal hernias. JSLS 13(3):327-331

271. Leibl BJ, Schmedt CG, Kraft K, Kraft B, Bittner R (2001) Laparoscopic transperitoneal hernia repair of incarcerated hernias: is it feasible? results of a prospective study. Surg Endosc 15(10):1179-1183

272. Mainik F, Flade-Kuthe R, Kuthe A (2005) Total extraperitoneal endoscopic hernioplasty (TEP) in the treatment of incarcerated and irresponsible inguinal and femoral hernias. Zentralbl Chir 130(6):550-553

273. Rebuffat C, Galli A, Scalambra MS, Balsamo F (2006) Laparoscopic repair of strangulated hernias. Surg Endosc 20(1): 131-134

274. Saggar VR, Sarangi R (2005) Endoscopic totally extraperitoneal repair of incarcerated inguinal hernia. Hernia 9(2):120-124

275. Ferzli G, Shapiro K, Chaudry G, Patel S (2005) Laparoscopic extraperitoneal approach to acutely incarcerated inguinal hernia. Surg Endosc 18(2):228-231

276. Ishihara T, Kubota K, Eda N, Ishibashi S, Haraguchi Y (1996) Laparoscopic approach to incarcerated inguinal hernia. Surg Endosc 10(11):1111-1113

277. Legnani GL, Rasini M, Pastori S, Sarli D (2008) Laparoscopic trans-peritoneal hernioplasty (TAPP) for the acute management of strangulated inguino-crural hernias: a report of nine cases. Hernia 12(2): 185-188

278. Sgourakis G, Radtke A, Sotiropoulos GC, Dedemadi G, Karaliotas C, Fouzas I, Karaliotas C (2009) Assessment of strangulated content of the spontaneously reduced inguinal hernia via hernia sac laparoscopy: preliminary results of a prospective randomized study. Surg Laparosc Endosc Percutan Tech 19(2):133-137

279. Taskin M, Zengin K, Unal E, Eren D, Korman U (2002) Laparoscopic repair of congenital diaphragmatic hernias. Surg Endosc 16(5):869

280. Dapri G, Himpens J, Hainaux B, Roman A, Stevens E, Capelluto E, Germay O, Cadière GB (2007) Surgical technique and complications during laparoscopic repair of diaphragmatic hernias. Hernia 11(2):179-183

281. Tagaya N, Tachibana M, Kijima H, Kakihara Y, Hamada K, Sawada T, Kubota K (2007) Laparoscopic treatment of paraesophageal hiatal hernia with incarceration of the pancreas and jejunum. Surg Laparosc Endosc Percutan Tech 17(4):313-316

282. Nattakom T, Schuerer D, Batra S, Velonovich V, Karmy-Jones R (1999) Emergency laparoscopic repair of a paraesophageal hernia. Surg Endosc 13(1):75-76

283. Chang CC, Tseng CL, Chang YC (2009) A surgical emergency due to an incarcerated paraesophageal hernia. Am J Emerg Med 27(1):134.e1-134.e3 
284. Cloyd DW (1994) Laparoscopic repair of incarcerated paraesophageal hernias. Surg Endosc 8(8):893-897

285. Sun HP, Chao YP (2010) Preoperative diagnosis and successful laparoscopic treatment of incarcerated obturator hernia. Hernia 14(2):203-206

286. Hunt L, Morrison C, Lengyel J, Sagar P (2009) Laparoscopic management of an obstructed obturator hernia: should laparoscopic assessment be the default option? Hernia 13(3):313-315

287. Velásquez-López JG, Gil FG, Jaramillo FE (2008) Laparoscopic repair of obturator bladder hernia: a case report and review of the literature. J Endourol 22(2):361-364

288. Wu JM, Lin HF, Chen KH, Tseng LM, Huang SH (2006) Laparoscopic preperitoneal mesh repair of incarcerated obturator hernia and contralateral direct inguinal hernia. J Laparoendosc Adv Surg Tech A 16(6):616-619

289. Yau KK, Siu WT, Chau CH, Yang PC, Li MK (2005) Laparoscopic management of incarcerated obturator hernia. Can J Surg 48(1):76-77

290. Cueto-García J, Rodríguez-Diaz M, Elizalde-Di Martino A, Weber-Sanchez A (1998) Incarcerated obturator hernia successfully treated by laparoscopy. Surg Laparosc Endosc 8(1): 71-73

291. Sarit C, Eliezer A, Mizrahi S (2003) Minimally invasive repair of recurrent strangulated umbilical hernia in cirrhotic patient with refractory ascites. Liver Transpl 9(6):621-622

292. Subramanya MS, Chakraborty J, Memon B, Memon MA (2010) Emergency intraperitoneal onlay mesh repair of incarcerated spigelian hernia. JSLS 14(2):275-278

293. López-Tomassetti Fernández EM, Martín Malagón A, Delgado Plasencia L, Arteaga González I (2006) Laparoscopic repair of incarcerated low spigelian hernia with transperitoneal PTFE DualMesh. Surg Laparosc Endosc Percutan Tech 16(6): 427-431

294. Yau KK, Siu WT, Chau CH, Yang GP, Li MK (2005) A laparoscopic approach for incarcerated Spigelian hernia. J Laparoendosc Adv Surg Tech A 15(1):57-59

295. Cissé M, Konaté I, Ka O, Dieng M, Dia A, Touré CT (2009) Internal supravesical hernia as a rare cause of intestinal obstruction: a case report. J Med Case Rep 3:9333

296. Mehran A, Szomstein S, Soto F, Rosenthal R (2004) Laparoscopic repair of an internal strangulated supravesical hernia. Surg Endosc 18(3):554-556

297. Gorgun E, Onur E, Baca B, Apaydin B, Yavuz N, Sirin F (2003) Laparoscopic repair of an internal supravesical hernia: a rare hernia causing small bowel obstruction. Surg Endosc 17(4):659

298. Khalaileh A, Schlager A, Bala M, Abugazala S, Elazary R, Rivkind AI, Mintz Y (2010) Left laparoscopic paraduodenal hernia repair. Surg Endosc 24(6):1486-1489

299. Bittner JG 4th, Edwards MA, Harrison SJ, Li K, Karmin PN, Mellinger JD (2009) Laparoscopic repair of a right paraduodenal hernia. JSLS 13(2):242-249

300. Uchiyama S, Imamura N, Hidaka $\mathrm{H}$, Maehara N, Nagaike K, Ikenaga N, Hotokezaka M, Chijiiwa K (2009) An unusual variant of a left paraduodenal hernia diagnosed and treated by laparoscopic surgery: report of a case. Surg Today 39(6):533-535

301. Jeong GA, Cho GS, Kim HC, Shin EJ, Song OP (2008) Laparoscopic repair of paraduodenal hernia: comparison with conventional open repair. Surg Laparosc Endosc Percutan Tech 18(6):611-615

302. Palanivelu C, Rangarajan M, Jategaonkar PA, Anand NV, Senthilkumar K (2008) Laparoscopic management of paraduodenal hernias: mesh and mesh-less repairs. A report of four cases. Hernia 12(6):649-653

303. Moon CH, Chung MH, Lin KM (2006) Diagnostic laparoscopy and laparoscopic repair of a left paraduodenal hernia can shorten hospital stay. JSLS 10(1):90-93
304. Antedomenico E, Singh NN, Zagorski SM, Dwyer K, Chung MH (2004) Laparoscopic repair of a right paraduodenal hernia. Surg Endosc 18(1):165-166

305. Uematsu T, Kitamura H, Iwase M, Yamashita K, Ogura H, Nakamuka T, Oguri H (1998) Laparoscopic repair of a paraduodenal hernia. Surg Endosc 12(1):50-52

306. Guillem P, Cordonnier C, Bounoua F, Adams P, Duval G (2003) Small bowel incarceration in a broad ligament defect. Surg Endosc 17(1):161-162

307. Kanbur AS, Ahmed K, Bux B, Hande T (2000) Jejunal obstruction and perforation resulting from herniation through broad ligament. J Postgrad Med 46(3):189-190

308. Nozoe T, Anai H (2002) Incarceration of small bowel herniation through a defect of the broad ligament of the uterus: report of a case. Surg Today 32(9):834-835

309. Agresta F, Michelet I, Candiotto E, Bedin N (2007) Incarcerated internal hernia of the small intestine through a breach of the broad ligament: two cases and a literature review. JSLS 11(2):255-257

310. Garcia-Oria M, Inglada J, Domingo J, Biescas J, Ching C (2007) Small bowel obstruction due to broad ligament hernia successfully treated by laparoscopy. J Laparoendosc Adv Surg Tech A 17(5):666-668

311. Hirokawa T, Hayakawa T, Tanaka M, Okada Y, Sawai H, Takeyama H, Manabe T (2007) Laparoscopic surgery for diagnosis and treatment of bowel obstruction: case report of paracecal hernia. Med Sci Monit 13(7):CS79-CS82

312. Omori H, Asahi H, Inoue Y, Irinoda T, Saito K (2003) Laparoscopic paracecal hernia repair. J Laparoendosc Adv Surg Tech A 13(1):55-57

313. Osadchy A, Keidar A, Zissin R (2005) Small bowel obstruction due to a paracecal hernia: computerized tomography diagnosis. Emerg Radiol 11(4):239-241

314. Rivkind AI, Shiloni E, Muggia-Sullam M, Weiss Y, Lax E, Freund HR (1986) Paracecal hernia: a cause of intestinal obstruction. Dis Colon Rectum 29(11):752-754

315. Kabashima A, Ueda N, Yonemura Y, Mashino K, Fujii K, Ikeda T, Tashiro H, Sakata H (2010) Laparoscopic surgery for the diagnosis and treatment of a paracecal hernia repair: report of acase. Surg Today 40(4):373-375

316. Van der Mieren G, de Gheldere C, Vanclooster P (2005) Transmesosigmoid hernia: report of a case and review of the literature. Acta Chir Belg 105(6):653-655

317. Gandhi AD, Patel RA, Brolin RE (2009) Elective laparoscopy for herald symptoms of mesenteric/internal hernia after laparoscopic Roux-en-Y gastric bypass. Surg Obes Relat Dis 5(2):144-149

318. Associazione Chirurghi Ospedalieri Italiani (ACOI) (2010) Proceedings of the Il trattamento laparoscopico del laparocele. 1 Consensus Conference Italiana (The laparoscopic treatment of hernia: a clear consensus? 1, Consensus Conference on the Laparoscopic Treatment of Hernia), Napoli, 14-15 January 2010

319. Landau O, Kyzer S (2004) Emergent laparoscopic repair of incarcerated incisional and ventral hernia. Surg Endosc 18:1374-1376

320. Franklin ME, Gonzalez JJ, Miter DB, Glass JL, Paulson D (2004) Laparoscopic diagnosis and treatment of intestinal obstruction. Surg Endosc 18:26-30

321. Shah RH, Sharma A, Khullar R, Soni V, Baijal M, Chowbey PK (2008) Laparoscopic repair incarcerated ventral abdominal wall hernia. Hernia 12:457-463

322. Szomstein S, Lo Menzo E, Simpfendorfer C, Zundel N, Rosenthal R (2006) Laparoscopic lysis of adhesions. World J Surg 30:535-540

323. Olmi S, Cesana G, Eba L, Croce E (2009) Emergency laparoscopic treatment of acute incarcerated incisional hernia. Hernia 3:605-608 
324. Raftopoulos I, Courcoulas AP (2007) Outcome of laparoscopic ventral hernia repair in morbidly obese patients with a body mass index exceeding $35 \mathrm{~kg} / \mathrm{m}^{2}$. Surg Endosc 21(12):2293-2297

325. Kirshtein B, Roy-Shapira A, Lantsberg L, Avinoach E, Mizrahi S (2005) Laparoscopic management of acute small bowel obstruction. Surg Endosc 19:464-467

326. Sharma A, Mehrotra M, Khullar R, Soni V, Baijal M, Chowbey PK (2008) Limited-conversion technique: a safe and viable alternative to conversion in laparoscopic ventral/incisional hernia repair. Hernia 12:367-371

327. Lujan HJ, Oren A, Plasencia G, Canelon G, Gomez E, Hernandez-Cano A, Jacobs M (2006) Laparoscopic management as the initial treatment of acute small bowel obstruction. JSLS 10:466-472

328. Strickland P, Lourie DJ, Suddleson EA, Blitz JB, Stain SC (1999) Is laparoscopy safe and effective for treatment of acute small-bowel obstruction? Surg Endosc 13:695-698

329. Carlson MA, Frantzides CT, Shostrom VK, Laguna LE (2008) Minimally invasive ventral herniorrhaphy: an analysis of 6,266 published cases. Hernia 12:9-22

330. Campanelli G, Catena F, Ansaloni L (2008) Prosthetic abdominal wall hernia repair in emergency surgery: from polypropylene to biological meshes. World J Emerg Surg 3:33

331. Parra MW, Rodas EB, Niravel AA (2011) Laparoscopic repair of potentially contaminated abdominal ventral hernias using a xenograft: a case series. Hernia 15(5):575-578

332. Franklin ME Jr, Trevino JM, Portollo G, Vela I, Glass JL, Gonzalez JJ (2008) The use of porcine small intestinal submucosa as a prosthetic material for laparoscopic hernia repair in infected and potentially contaminated fields: long-term follow up. Surg Endosc 22:1941-1946

333. Uranüs S, Dorr K (2010) Laparoscopy in abdominal trauma. Eur J Trauma Emerg Surg 36:19-24

334. Sudakoff GS, Yucel EK, Rosen MP, Francis IR, Baum RA, Foley WD, Gay SB, Greene FL, Mansour MA, Rybicki FJ (2008) Expert panels on vascular imaging, gastrointestinal imaging, and urologic imaging. ACR Appropriateness Criteria ${ }^{\circledR}$ blunt abdominal trauma [online publication]. American College of Radiology (ACR), Reston, VA

335. Leppäniemi A, Haapiainen R (2003) Diagnostic laparoscopy in abdominal stab wounds: a prospective, randomized study. J Trauma 55(4):636-645

336. National Guideline Clearinghouse, Agency for Healthcare Research and Quality, Diagnostic laparoscopy for trauma. Guideline Summary NGC 6829. AHRQ, DHHS, Rockville, MD

337. Choi YB, Lim KS (2003) Therapeutic laparoscopy for abdominal trauma. Surg Endosc 17:421-427

338. Weinberg JA, Magnotti LJ, Edwards NM, Claridge JA, Minard G, Fabian TC, Croce MA (2007) "Awake" laparoscopy for the evaluation of equivocal penetrating abdominal wounds. Injury 38(1):60-64

339. Warren O, Kinross J, Paraskeva P, Darzi A (2006) Emergency laparoscopy—current best practice. World J Emerg Surg 1:24

340. Smith RS, Fry WR, Morabito DJ, Koehler RH, Organ CH Jr (1995) Therapeutic laparoscopy in trauma. Am J Surg 170:632-637

341. Matthews BD, Bui H, Harold KL, Kercher KW, Adrales G, Park A, Sing RF, Heniford BT (2003) Laparoscopic repair of traumatic diaphragmatic injuries. Surg Endosc 17:254-258

342. Smith CH, Novick TL, Jacobs DG, Thomason MH (2000) Laparoscopic repair of a ruptured diaphragm secondary to blunt trauma. Surg Endosc 14:501-502

343. Zantut LF, Ivatury RR, Smith RS, Kawahara NT, Porter JM, Fry WR, Poggetti R, Birolini D, Organ CH Jr (1997) Diagnostic and therapeutic laparoscopy for penetrating abdominal trauma: a multicenter experience. J Trauma 42:825-831
344. Mathonnet M, Peyrou P, Gainant A, Bouvier S, Cubertafond P (2003) Role of laparoscopy in blunt perforations of the small bowel. Surg Endosc 17:641-645

345. Fabian TC, Croce MA, Stewart RM, Pritchard FE, Minard G, Kudsk KA (1993) A prospective analysis of diagnostic laparoscopy in trauma. Ann Surg 217:557-565

346. Chen RJ, Fang JF, Lin BC, Hsu YB, Kao JL, Kao YC, Chen MF (1998) Selective application of laparoscopy and fibrin glue in the failure of nonoperative management of blunt hepatic trauma. J Trauma 44:691-695

347. Marks JM, Youngelman DF, Berk T (1997) Cost analysis of diagnostic laparoscopy vs laparotomy in the evaluation of penetrating abdominal trauma. Surg Endosc 11:272-276

348. Meng X, Liu L, Jiang H (2010) Indications and procedures for second-look surgery in acute mesenteric ischemia. Surg Today 40(8):700-705

349. Brandt LJ, Boley SJ (2000) AGA technical review on intestinal ischemia. American Gastrointestinal Association. Gastroenterology 118(5):954-968

350. Zamir G, Reissman P (1998) Diagnostic laparoscopy in mesenteric ischemia. Surg Endosc 12(5):390-393

351. Menke J (2010) Diagnostic accuracy of multidetector CT in acute mesenteric ischemia: systematic review and meta-analysis. Radiology 256(1):93-101

352. Baeshko AA, Bondarchuk AG, Podymako NS, Sologub IM, Krukovich EA (2000) Laparoscopy in diagnosis of intestinal mesentery acute circulatory disturbance. Khirurgiia (Mosk) 5:18-20

353. Paral J, Ferko A, Plodr M, Raupach J, Hadzi-Nikolov D, Dolezal D, Chovanec V (2007) Laparoscopic diagnostics of acute bowel ischemia using ultraviolet light and fluorescein dye: an experimental study. Surg Laprosc Endosc Percutan Tech 17(4):291295

354. Paral J, Subrt Z, Lochman P, Ferko A, Dusek T, Slaninka I, Cecka F, Louda M, Romzova M, Jon B, Kaska M (2009) Peroperative diagnostics of acute bowel ischemia using ultraviolet light and fluorescein dye. Rozhl Chir 88(10):590-595

355. Jaramillo EJ, Trevino JM, Berghoff KR, Franklin ME Jr (2006) Bedside diagnostic laparoscopy in the intensive care unit: a 13-year experience. JSLS 10(2):155-159

356. Yanar H, Taviloglu K, Ertekin C, Ozcinar B, Yanar F, Guloglu R, Kirtoglu M (2007) Planned second-look laparoscopy in the management of acute mesenteric ischemia. World J Gastroenterol 13(24):3350-3353

357. Palanivelu C, Rangarajan M, Maheshkumaar GS, Rajan PS (2008) Relaparoscopy in the management of acute abdomen due to localized ischemic bowel: a novel technique-case report. Int J Surg 6(6):89-91

358. Bottger TC, Hermeneit S, Muller M, Terzic A, Rodehorst A, Elad L, Schamberger M (2009) Modifiable surgical and anesthesiologic risk factors for the development of cardiac and pulmonary complications after laparoscopic colorectal surgery. Surg Endosc 23:2016-2025

359. Jenkins ED, Yom VH, Melman L, Pierce RA, Schuessler RB, Frisella MM, Eagon JC, Brunt LM, Matthews BD (2010) Clinical predictors of operative complexity in laparoscopic ventral hernia repair: a prospective study. Surg Endosc 24:1872-1877

360. Ji YK, Cheung SS, Hong SK, Wol SJ, Hyun JK (2010) Positive end-expiratory pressure in pressure-controlled ventilation improves ventilatory and oxygenation parameters during laparoscopic cholecystectomy. Surg Endosc 24:1099-1103

361. da Luz Moreira A, Kiran RP, Kirat HT, Remzi FH, Geisler DP, Church JM, Garofalo T, Fazio VW (2010) Laparoscopic versus open colectomy for patients with American Society of Anesthesiology (ASA) classifications 3 and 4: the minimally invasive 
approach is associated with significantly quicker recovery and reduced costs. Surg Endosc 24:1280-1286

362. Lawrence VA, Cornell JE, Smetana GW (2006) American College of Physicians. Strategies to reduce postoperative pulmonary complications after noncardiothoracic surgery: systematic review for the American College of Physicians. Ann Intern Med 144:596-608

363. Patel GN, Rammos CK, Patel JV, Estes NC (2010) Further reduction of hospital stay for laparoscopic colon resection by modifications of the fast-track care plan. Am J Surg 199:391-395

364. Gerges FJ, Kanazi GE, Jabbour-Khoury SI (2006) Anesthesia for laparoscopy: a review. J Clin Anesth 18:67-78

365. Gramatica L Jr, Brasesco OE, Mercado Luna A (2002) Laparoscopic cholecystectomy performed under regional anesthesia in patients with chronic obstructive pulmonary disease. Surg Endosc 16(3):472-475

366. Pursnani KG, Bazza Y, Calleja M, Mughal MM (1998) Laparoscopic cholecystectomy under epidural anesthesia in patients with chronic respiratory disease. Surg Endosc 12(8):1082-1084

367. Azurin DJ, Go LS, Cwik JC, Schuricht AL (1996) The efficacy of epidural anesthesia for endoscopic preperitoneal herniorrhaphy: a prospective study. J Laparoendosc Surg 6(6):369-373

368. Vaghadia H, McLeod DH, Mitchell GW, Merrick PM, Chilvers CR (1997) Small-dose hypobaric lidocaine-fentanyl spinal anesthesia for short duration outpatient laparoscopy. I. A randomized comparison with conventional dose hyperbaric lidocaine. Anesth Analg 84(1):59-64

369. Chilvers CR, Vaghadia H, Erle Mitchell GW, Merrick PM (1997) Small-dose hypobaric lidocaine-fentanyl spinal anesthesia for short duration outpatient laparoscopy. II. Optimal dose. Anesth Analg 84(1):65-70

370. Vaghadia H, Viskari D, Mitchell GW, Berrill A (2001) Selective spinal anesthesia for outpatient laparoscopy. I: characteristics of three hypobaric solutions. Can J Anaesth 48(3):256-260

371. Lennox PH, Vaghadia H, Henderson C, Martin L, Mitchell GW (2002) Small-dose selective spinal anesthesia for short-duration outpatient laparoscopy: recovery characteristics compared with desflurane anesthesia. Anesth Analg 94(2):346-350

372. Stewart AV, Vaghadi H, Collins L, Mitchell GW (2001) Smalldose selective spinal anaesthesia for short-duration outpatient gynaecological laparoscopy: recovery characteristics compared with propofol anaesthesia. Br J Anaesth 86(4):570-572

373. Spivak H, Nudelman I, Fuco V, Rubin M, Raz P, Peri A, Lelcuk S, Eidelman LA (1999) Laparoscopic extraperitoneal inguinal hernia repair with spinal anesthesia and nitrous oxide insufflation. Surg Endosc 13(10):1026-1029

374. Hamad MA, El-Khattary OA (2003) Laparoscopic cholecystectomy under spinal anesthesia with nitrous oxide pneumoperitoneum: a feasibility study. Surg Endosc 17(9):1426-1428

375. Naja MZ, Ziade MF, Lonnqvist PA (2004) General anaesthesia combined with bilateral paravertebral blockade (T5-6) vs. general anaesthesia for laparoscopic cholecystectomy: a prospective, randomized clinical trial. Eur J Anaesthesiol 21(6):489-495

376. Neudecker C, Sauerland S, Neugebauer E, Bergamaschi R, Bonjer HJ, Cuschieri A, Fuchs KH, Jacobi Ch, Jansen FW, Koivusalo AM, Lacy A, MacMahon MJ, Millat B, Schwenk W (2002) The European Association for Endoscopic Surgery clinical practice guideline on the pneumoperitoneum for laparoscopic surgery. Surg Endosc 16:1121-1143

377. Popken CA, Compton RP, Walter DN, Browder IW (1995) Benefits of pulmonary artery catheter and transesophageal echocardiographic monitoring in laparoscopic cholecystectomy patients with cardiac disease. Am J Surg 169:202-207

378. Mallat AF, Mancini ML, Daley BJ, Enderson BL (2008) The role of laparoscopy in trauma: a ten-year review of diagnosis and therapeutics. Am Surg 74(12):1166-1170
379. Mimica Z, Biocic M, Babic A, Banovic I, Tocilj J, Radonic V, Ilic N, Petricevic A (2001) Laparoscopic and laparotomic cholecystectomy: a randomized clinical trial comparing postoperative respiratory function. Respiration 67:153-158

380. Koivusalo AM, Lindgren L (2000) Effects of carbon dioxide pneumoperitoneum for laparoscopic cholecystectomy. Acta Anaesthesiol Scand 44:834-841

381. Ordemann J, Jacobi C, Schwenk W, Stösslein R, Müller JM (2001) Cellular and humoral inflammatory response after laparoscopic and conventional colorectal resections-results of prospective randomized trial. Surg Endosc 15:600-608

382. Rauh R, Hemmerling TM, Rist M, Jacobi KE (2001) Influence of pneumoperitoneum and patient positioning on respiratory system compliance. J Clin Anesth 13:361-365

383. O'Malley C, Cunningham AJ (2001) Physiologic changes during laparoscopy. Anesthesiol Clin North America 19:1-19

384. Koivusalo AM, Lindgren L (1999) Respiratory mechanics during laparoscopic cholecystectomy. Anesth Analg 89:800-806

385. Yacoub OF, Cardona I Jr, Coveler LA, Dodson MG (1982) Carbon dioxide embolism during laparoscopy. Anesthesiology 57:533-535

386. Pl Tan, Lee TL, Tweed WA (1992) Carbon dioxide absorption and gas exchange during pelvic laparoscopy. Cand J Anaesth 39:677-681

387. Stuttmann R, Vogt C, Eypasch E, Doehn M (1995) Haemodynamic changes during laparoscopic cholecystectomy in the high risk patient. Endosc Surg Allied Technol 3:174-179

388. Koivusalo AM, Kellokumpu I, Scheinin M, Tikkanen I, Mäkisalo H, Lindgren L (1998) A comparison of gasless mechanical and conventional carbon dioxide pneumoperitoneum methods for laparoscopic cholecystectomy. Anesth Analg 86:153-158

389. Dexter SP, Vucevic M, Gibson J, McMahon MJ (1999) Hemodynamic consequences of high- and low-pressure capnoperitoneum during laparoscopic cholecystectomy. Surg Endosc $13: 376-381$

390. Nordentoft T, Bringstrup FA, Bremmelgaard A, Stage JG (2000) Effect of laparoscopy on bacteremia in acute appendicitis: a randomized controlled study. Surg Larparosc Endosc Percutan Tech 10:302-304

391. Bloomfield GL, Ridings PC, Blocher CR, Marmarou A, Sugerman HJ (1996) Effects of increased intra-abdominal pressure upon intracranial and cerebral perfusion-pressure before and after volume expansion. J Trauma 40:936-941

392. Valenza F, Chevallard G, Fossali T, Salice V, Pizzocri M, Gattinoni L (2010) Management of mechanical ventilation during laparoscopic surgery. Best Pract Res Clin Anaesth $24: 227-241$

393. Almarakbi WA, Fawzi HM, Alhashemi JA (2009) Effects of four intraoperative ventilatory strategies on respiratory compliance and gas exchange during laparoscopic gastric banding in obese patients. Br J Anaesth 102(6):862-868

394. Balick-Weber CC, Nicolas P, Hedreville-Montout M, Blanchet P, Stéphan F (2007) Respiratory and haemodynamic effects of volume-controlled vs pressure-controlled ventilation during laparoscopy: a cross over study with echocardiographic assessment. Br J Anaesth 99:429-435

395. De Baerdemaeker LE, Van der Herten C, Gillardin JM, Pattyn P, Mortier EP, Szegedi LL (2008) Comparison of volume-controlled and pressure-controlled ventilation during laparoscopy gastric banding in morbidly obese patients. Obesity Surg 18:680-685

396. Fahy BG, Barnas GM, Nagle SE, Flowers JL, Njoku MJ, Agarwal M (1996) Effects of Trendelenburg and reverse Trendelenburg postures on lung and chest wall mechanics. J Clin Anesth 8:236-244 
397. Gehring H, Kuhmann K, Klotz KF, Ocklitz E, Roth-Isigkeit A, Sedemund-Adib B, Schmucker P (1998) Effects of propofol vs isoflurane on respiratory gas exchange during laparoscopic cholecystectomy. Acta Anaesth Scand 42:189-194

398. Merkow RP, Bilimoria KY, McCarter MD, Bentrem DJ (2009) Effect of body mass index on short-term outcomes after colectomy for cancer. J Am Coll Surg 208:53-61

399. Scheidbach H, Benedix F, Hügel O, Kose D, Köckerling F, Lippert H (2008) Laparoscopic approach to colorectal procedures in the obese patient: risk factor or benefit? Obes Surg 18:66-70

400. Dumont L, Mattys M, Mardirosoff C, Vervloesem N, Alle JL, Massaut J (1997) Changes in pulmonary mechanics during laparoscopic gastroplasty in morbidly obese patients. Acta Anaesthesiol Scand 41:408-413

401. Casati A, Comotti L, Tommasino C, Leggieri C, Bignami E, Tarantino F, Torri G (2000) Effects of pneumoperitoneum and reverse Trendelenburg position on cardiopulmonary function in morbidly obese patients receiving laparoscopic gastric banding. Eur J Anaesthesiol 17:300-305

402. Hedenstierna G, Edmark L (2005) The effects of anesthesia and muscle paralysis on the respiratory system. Intensive Care Med 31:1327-1335

403. Hedenstierna G, Rothen HU (2000) Atelectasis formation during anesthesia: causes and measures to prevent it. J Clin Monit Comput 16:329-335

404. Pelosi P, Croci M, Ravagnan I, Vicardi P, Gattinoni L (1996) Total respiratory system, lung, and chest wall mechanics in sedated-paralyzed postoperative morbidly obese patients. Chest 109:144-1451
405. Putensen-Himmer G, Putensen C, Lammer H, Lingnau W, Aigner F, Benzer H (1992) Comparison of postoperative respiratory function after laparoscopy or open laparotomy for cholecystectomy. Anesthesiology 77:675-680

406. Cunningham A, Brull S (1993) Laparoscopic cholecystectomy: anesthetic implications. Anesth Analg 76:1120-1125

407. AL-Fozan H, Tulandi T (2002) Safety and risks of laparoscopy in pregnancy. Curr Opin Obstet Gynecol 14:375-379

408. Hardwick RH, Slade RR, Smith PA, Thompson MH (1999) Laparoscopic splenectomy in pregnancy. J Laparoendosc Adv Surg Tech 9:439-440

409. Demeure MJ, Carlen B, Traul D, Budney C, Lalande B, Lipinski A, Cruikshank D, Kotchen T, Wilson S (1998) Laparoscopic removal of a right adrenal pheochromocytoma in a pregnant woman. J Laparoendosc Adv Surg Tech 8(5):315-319

410. Sagiv R, Debby A, Sadan O, Malinger G, Glezerman M, Golan A (2001) Laparoscopic surgery for extrauterine pregnancy in hemodynamically unstable patients. J Am Assoc Gynecol Laparosc 8:529-532

411. Steinbrook RA, Brooks DC, Datta S (1996) Laparoscopic cholecystectomy during pregnancy. Surg Endosc 10(5):511-515

412. Bhavani-Shankar K, Steinbrook RA (1998) Anesthetic considerations for minimally invasive surgery. In: Brooks DC (ed) Current review of minimally invasive surgery, 2nd edn. Current Medicine, Philadelphia, p 29

413. SAGES (1998) Guidelines for laparoscopic surgery during pregnancy. Surg Endosc 12(2):189-190 